\title{
On constraining a lumped hydrological model with both piezometry and streamflow: results of a large sample evaluation
}

\author{
Antoine Pelletier ${ }^{1,2}$ and Vazken Andréassian ${ }^{2}$ \\ ${ }^{1}$ École des Ponts, Marne-la-Vallée, France \\ ${ }^{2}$ Université Paris-Saclay, INRAE, UR HYCAR, Antony, France \\ Correspondence: Antoine Pelletier (antoine.pelletier@inrae.fr)
}

\begin{abstract}
The role of aquifers in the seasonal and multiyear dynamics of streamflow is undisputed: in many temperate catchments, aquifers store water during the wet periods and release it all year long, making a major contribution to low flows. The complexity of groundwater modelling has long prevented surface hydrological modellers from including groundwater level data, especially in lumped rainfall-runoff models. In this article, we investigate whether using groundwater level data in the daily GR6J model, through a composite calibration framework, can improve the performance of streamflow simulation. We tested the new calibration process on 107 French catchments. Our results show that these additional data are superfluous for streamflow simulation, since for catchments, model performance is not significantly improved. However, parameter stability is ameliorated and the model shows a surprising ability to simulate groundwater level with a satisfying performance, in a wide variety of hydrogeological and hydroclimatic contexts. Finally, we make several recommendations regarding the model calibration process to be used in a given situation.
\end{abstract}

\section{Introduction}

\subsection{Why use piezometry in low-flow modelling?}

"Geology is the fundamental base of hydrology" (Castany, 1963): hydrological processes taking place underground are an essential part of the behaviour of many hydrological systems. At the catchment scale, aquifers have the ability to store water in the long run and to release it afterwards, thereby contributing to streamflow. The complex water cycle underground processes are often aggregated in surface hydrology models by a simple reservoir, which fills during each rainfall event and slowly empties during rainless periods. This conceptualisation is called into question by the ability of underground water to contribute heavily to flood events - see e.g. Habets et al. (2010), Roche et al. (2012) or Guérin et al. (2019) - but it remains an acceptable representation of aquifer-river exchanges during droughts. Indeed, the fundamental role of aquifers in supporting river flows during the dry season is obvious: Carlier et al. (2018) and Wirth et al. (2020) linked low-flow statistics to hydrogeological descriptors in Swiss catchments and reported that their low-flow behaviour was heavily dependent on the geological context, with a particular role of sandstone and quaternary aquifers in inter-seasonal water storage; Tague and Grant (2009) and Hayashi (2020) showed the buffering role of small aquifers in mountainous catchments and underlined their ability to support low flows and to supplement the snow reservoir that is dried up by climate change. Tobin and Schwartz (2020) and Käser and Hunkeler 

during long dry periods. Tracer studies (see e.g. Soulsby et al., 2006; Tobin and Schwartz, 2020) confirmed that groundwater contributes significantly to streamflow during the dry season and that the extent of this contribution depends on the hydrogeological configuration, i.e. the geological nature of the catchment's subsoil. The buffering or storage role of aquifers contributes to the phenomenon known as catchment memory, i.e. the smoothing of the input climatic signal by the catchment response (Tomasella et al., 2008; Lo and Famiglietti, 2010; Creutzfeldt et al., 2012). Using other words, Roche et al. (2012) highlight that, at least in temperate regions, severe droughts are often the result of several drier-than-normal years that lead to aquifers reaching exceptionally low levels.

Despite the level of evidence of the role of aquifers in low-flow dynamics, many hydrological modelling tools that are commonly - and quite successfully - used to simulate and forecast droughts have no explicit representation of groundwater dynamics. The cultural differences between the hydrogeology community and the surface hydrology community, highlighted by Barthel (2014), contribute to this situation: different systems with different characteristics and different problems to be solved lead to different models whose coupling is not straightforward. In particular, the main goal of surface hydrology modelling - streamflow - is almost directly and dynamically accessible, which makes elementary calibration of all kinds of models possible, while measuring the state of an aquifer is only possible using a limited number of point piezometers that measure the hydraulic head. Satellite remote sensing is now able to monitor groundwater change (Swenson et al., 2006; Syed et al., 2008) but the temporal availability and the spatial resolution of such products limit their use in hydrological modelling at local to regional scales.

The difficulty in using piezometric data is one of the reasons why hydrologists often prefer to retrieve the river-groundwater flux by solving the inverse problem, i.e. using the surface data to infer the state of the aquifer. The most common approach is hydrograph separation, which consists in splitting streamflow into two components: a slow one, named baseflow and a quick one, named quickflow. Baseflow is then regarded as the result of the slowest hydrological processes operating in the catchment, generally underground processes. This approach can be useful for analysing the hydrological behaviour of large sets of catchments and a high proportion of baseflow in total streamflow is often correlated with a geological context favourable to a high contribution of aquifers (Pelletier and Andréassian, 2020). However, assimilating conceptual baseflow into aquifer contribution is generally unsuitable (Beven, 1991), since it results from a confusion between catchment time response and water molecule transit time (McDonnell and Beven, 2014). To provide a hydrological model with new information about the catchment state, here its underground state, it is necessary to provide new data, such as, when it is available, piezometry.

\subsection{What are the existing modelling approaches?}

Hydrological models are often classified depending on their level of spatial discretisation - lumped versus distributed models 55 - and their ambition to represent more or less explicitly the physical processes taking place in the catchment - conceptual versus physically based models - (Roche et al., 2012). Lumped models have no spatial discretisation at the catchment scale - i.e. the catchment is treated as a single unit with spatially averaged descriptors - whereas distributed models discretise the catchment into grid units, each of them described by several variables (Beven, 2012). Semi-distributed models constitute an 
intermediate option, in which the catchment under study is divided into sub-catchments, each of them becoming the object of lumped computations (see e.g. de Lavenne et al., 2016). Physically based or process-based models strive to reproduce the physical processes taking place in the catchment, by solving a version of fluid mechanics equations, while conceptual models develop their own empirical equations to reproduce the total water balance without any reductionist ambition. Because every grid element of a distributed model needs to be parametrised, it usually carries a large number of parameters that cannot all be calibrated on observations and need to be set a priori; lumped models, on the other hand, often have a smaller number of parameters that are easier to calibrate automatically from observations. Since physical laws need to be solved at local scale and lumped models are generally designed for their simplicity in operational purposes, there is a general correspondence between distributed and physically based models on the one hand and lumped and conceptual models on the other (Beven, 2012).

Hydrogeological models dedicated to groundwater simulation are generally physically based - see Mackay et al. (2014) for a rare example of conceptual model. Therefore, the surface/groundwater interaction is more naturally represented in physically based distributed hydrological models (Dassargues et al., 1999). At local scale, this can be achieved by fluid mechanics equations (Bartlett and Porporato, 2018) but at catchment scale, distributed models generally use simplified versions of these equations. Barthel and Banzhaf (2015) performed an extensive review of models taking into account the surface/groundwater interaction at regional scale. We will not summarise the review here, but a salient point is the distinction between fully coupled schemes, where equations are solved simultaneously for surface and groundwater flows (see e.g. HydroGeoSphere by Brunner and Simmons, 2011), and loosely coupled schemes, where several models are coupled only via the exchange of results (see e.g. Isba-Modcou in Habets et al., 2010). All these approaches are difficult to implement on large sets of catchments, because of parametrisation requirements.

Using conceptual lumped rainfall-runoff models to simulate the surface/groundwater interaction is less straightforward, since fluid mechanics equations cannot be used; a conceptual representation of the aquifer, often using a reservoir, is therefore necessary. Water exchange with an aquifer can be computed solving the inverse problem, i.e. inferring the fluxes from the amount of water needed by the model to close the water budget - see e.g. Perrin et al. (2003), Le Moine (2008), Le Moine et al. (2008) and Herron and Croke (2009) - but it is far from sufficient for simulating the actual level of an aquifer. Bergström and Sandberg (1983) added a groundwater simulation module to the HBV model (Bergström and Forsman, 1973) and implemented it on three aquifers; they obtained a satisfactory performance in reproducing past piezometric time series, despite parametrisation issues caused by computation cost, which are no longer mentioned in recent studies (Széles et al., 2020). Thiéry (1988) used the ground reservoir of the Gardenia model (Thiéry, 2014) to simulate and forecast the piezometry of the Paris basin chalk aquifer, using a linear regression between the reservoir levels and the aquifer levels. Borzì et al. (2019) designed a modified version of the IHACRES model (Jakeman and Hornberger, 1993) with an explicit representation of a volcanic deep aquifer in Sicily, through an additional conceptual reservoir. In order to represent the specific role of groundwater in intermittent streams, 90 Moore and Bell (2002) added a piezometry simulation module to the PDM rainfall-runoff model (Moore, 1999), which was able to represent pumped abstractions. The path followed by Hughes (2004) and Efstratiadis et al. (2008) is intermediate, with a semi-distributed conceptual hydrological model connected to a semi-distributed - with a different spatial discretisation conceptual aquifer representation; this model is easier to implement and needs fewer data than a fully distributed one, allowing 
for many experiments simulating anthropic influence, but it is far from straightforward to implement on any catchment with few data.

These modelling schemes have shown noteworthy simulation abilities for both aquifers and streamflow. However, they have not been tested on large sets of catchments in various contexts to value their robustness and generalisation capacity. Moreover, groundwater simulation is, in most studies, a side product of rainfall-runoff modelling. There is little evidence on how the addition of groundwater data can actually help obtain a better streamflow simulation.

\subsection{How are measured data used in hydrological modelling?}

Most hydrological models are parametric and their parameters are calibrated using measured streamflow data (Roche et al., 2012). To find the best set of parameters with which to reproduce the streamflow time series, a calibration criterion, which is a function of measured and simulated - or forecasted - streamflow, is optimised, the most common one being the NashSutcliffe efficiency or NSE (Nash and Sutcliffe, 1970). Gupta et al. (2009) and Kling et al. (2012), investigating the drawbacks of NSE, proposed another criterion, henceforth known as Kling-Gupta efficiency (KGE), which is a Euclidean combination of three criteria that all compare measured and simulated streamflow. Computed with untransformed time series, these criteria are focused on the peaks of the hydrograph; to get a better calibration on the lower part of the latter, i.e. low flows, streamflow time series can be transformed using concave functions (Pushpalatha et al., 2012), such as square root or logarithm.

Traditional calibration approaches are generally single-objective, i.e. only one objective function is used. However, all criteria can be regarded as flawed, since they focus on only one aspect of the hydrograph representation. Linear or Euclidean combinations of criteria can be used (Nicolle et al., 2014), for instance the mean between NSE and KGE, which is called composite calibration. Multi-objective calibration (Madsen, 2003) tries to optimise several criteria at the same time. It is generally impossible to get a unique optimal set of parameters as the result of a multi-objective calibration problem; a Pareto front, i.e. an ensemble of parameter sets, is formed, each one representing a different compromise between objective functions. For operational purposes, it is necessary to choose a parameter set in this Pareto front, generally using a determined weighting between objective functions - either a linear combination or a Euclidean distance to a reference point - which is similar to composite calibration.

Complex, distributed hydrological models, overall when they claim to be physically based, often explicitly simulate physical variables than can be easily coerced to correspond to measured data. Even if they are rarely available on large sets of catchments, in-field measurements are often used in models for specific instrumented catchments. For instance, the isoWATFLOOD model (Stadnyk et al., 2013; Stadnyk and Holmes, 2020) is calibrated using both streamflow and isotopic - $\delta^{18} O-$ data, but a visual evaluation of calibration is necessary; Jian et al. (2017) used, in a catchment where only few streamflow measurements were available, river level data and added three new parameters to a hydrological model to simulate the rating curve. Whereas infield measurements are not always common, satellite data are broadly available around the world and numerous studies have used them in hydrological models: Immerzeel and Droogers (2008) used satellite evaporation to calibrate the SWAT distributed model through a composite criterion and got a closer representation of actual evaporation and less equifinality in parameter determination; Mostafaie et al. (2018) performed a multi-objective calibration using NSE for streamflow and total water storage 
from GRACE satellite data; Milzow et al. (2011) combined several satellite datasets - surface soil moisture, radar altimetry and total water storage - to calibrate a semi-distributed model in a catchment which few streamflow measurements through a composition of nine criteria; Demirel et al. (2019) explored different combinations of objective functions, computed on several satellite products measuring soil moisture and water storage, to calibrate a conceptual model, with little gain on the streamflow simulation performance; Dembélé et al. (2020) performed a composite calibration of a distributed model with four datasets - measured streamflow and satellite evaporation, soil moisture and water storage - and improved the model representation of processes at the expense of a small degradation of the streamflow simulation performance.

Using other data than streamflow is less straightforward in empirical or conceptual models that do not explicitly simulate physical fluxes or states. A particular state of the model is generally linked to the available physical variable. In catchments affected by snow and/or glaciers, related data - i.e. snow depth or glacier state - can be used in model calibration (Riboust et al., 2018; Tiel et al., 2020). Beyond calibration, extra data can be assimilated into the model to correct its trajectory during runtime; several studies showed an improved performance of hydrological models with assimilation of soil moisture (Aubert et al., 2003a, b; Oudin et al., 2003) or snowpack (Thirel et al., 2013).

As far as piezometry is concerned, distributed hydrological models are rarely calibrated using piezometry time series. Most gridded models have a physical parametrisation: parameter values are, directly or indirectly, inferred from local properties measured in situ (Moreda et al., 2006) - for instance, topography, soil types, vegetation or geological properties. At a pinch, the parameter set can be adjusted, with a limited variation margin adapted to the physicalness of parameters, to better represent streamflow; but given the often large number of parameters to be adjusted, distributed models cannot be fully calibrated without suffering from equifinality (Beven, 1993). In these conditions, several studies underlined the possibility of calibrating a distributed hydrological model using both piezometry and streamflow, with semi-automatic (Feyen et al., 2000; El-Nasr et al., 2005; Li et al., 2017) or automatic multi-objective calibration procedures (Khu et al., 2008). Lumped conceptual models, with a reduced number of parameters, are easier to calibrate directly without prior determination of the parameters. When a particular state of the model, in general a groundwater reservoir, can be coerced to a measured piezometry time series, calibration using both piezometry and streamflow is possible, generally through a linear composite objective function combining criteria on streamflow and piezometry (Thiéry, 1988; Moore and Bell, 2002; Széles et al., 2020). Despite significant improvemenst in piezometry simulation, these studies found that adding piezometric information to the calibration process had little influence on streamflow simulation.

\subsection{Scope of the paper}

In view of the undisputed role of aquifers in low-flow dynamics in many catchments, it seems reasonable to try to improve the performance of a hydrological model by adding piezometric data to the calibration process. However, most of the approaches reviewed in the previous section are difficult to implement due to a relatively large number of parameters and because the performance gain offered by the new data has not been assessed on a large set of catchments, which is necessary for model evaluation (Barthel and Banzhaf, 2015). 
In this study, we aim to develop a new modelling approach based on a simple structure with an easy parametrisation, assessed on a large sample of catchments to ensure the generality of conclusions. We propose an adaptation of the structure of the daily rainfall-runoff model GR6J (Pushpalatha et al., 2011) to make it simulate groundwater table levels. Section 2 recounts the process that led to designing this adaptation and the calibration and evaluation schemes of the new model. Section 3 presents the hydroclimatic dataset of 107 catchments over mainland France that was used to evaluate the new calibration with respect to the original one, performed only on streamflow. Section 4 summarises the results and proposes recommendations for model calibration in various contexts.

\section{Hydroclimatic dataset}

\subsection{Context}

The French mainland territory hosts a large diversity of climatic, topographic and geological contexts, with catchments representing various hydrological and hydrogeological configurations. Several major aquifers are known to have a significant influence on surface waters, especially on low flows. The Paris basin, with its pile of secondary and tertiary sedimentary formations, hosts several major aquifers for surface hydrology: the Late Cretaceous chalk aquifer is known to govern the multiyear dynamics of the Somme and part of the Seine and Loire basins, with a noteworthy long flood event after the exceptionally wet years of 1999 and 2000 (Pinault et al., 2005; Habets et al., 2010); the Beauce tertiary limestone aquifer controls the hydrology of a key agricultural region astride the Loire and the Seine basin, with a major groundwater contribution to low flows (Lalot et al., 2015); the Cenomanian sand aquifer in the Perche region, which is directly connected to the Eure and Huisne basins, is regarded as an essential groundwater reserve for the region and its declining trend is a major threat for Perche rivers (Lenhardt et al., 2009). The second largest French sedimentary basin, the Aquitaine Basin, has a more complex configuration with thick multi-layer aquifers covered by poorly permeable formations, such as Pyrenean molasses. The outcropping areas of these formations are visible in figure 1.

The large sedimentary basins are not the only geological areas in France which host aquifers that are of interest for surface hydrology modelling. Aquifers located in alluvial plains, such as the international Rhineland aquifer - and its French part in the Alsace plain quaternary alluvium - or the Bresse graben gravels, play a major role in the streamflow dynamics of the Saone and the Rhine basins. As highlighted in the Introduction, even small alluvial aquifers outside plains can have an influence on rivers: for example, several small left-bank tributaries of the Rhone are mostly ruled by the Bièvre moraine aquifer, with visible consequences on water quality (Bel et al., 1999). Regions in which geological formations are composed of metamorphic or igneous rocks, such as Brittany or the Ardennes, can host fractured bedrock aquifers, linked to surface rivers. The wide monitoring network of rivers and groundwater in France, described below, allowed us to select a test sample of catchments which is representative of this diversity. 


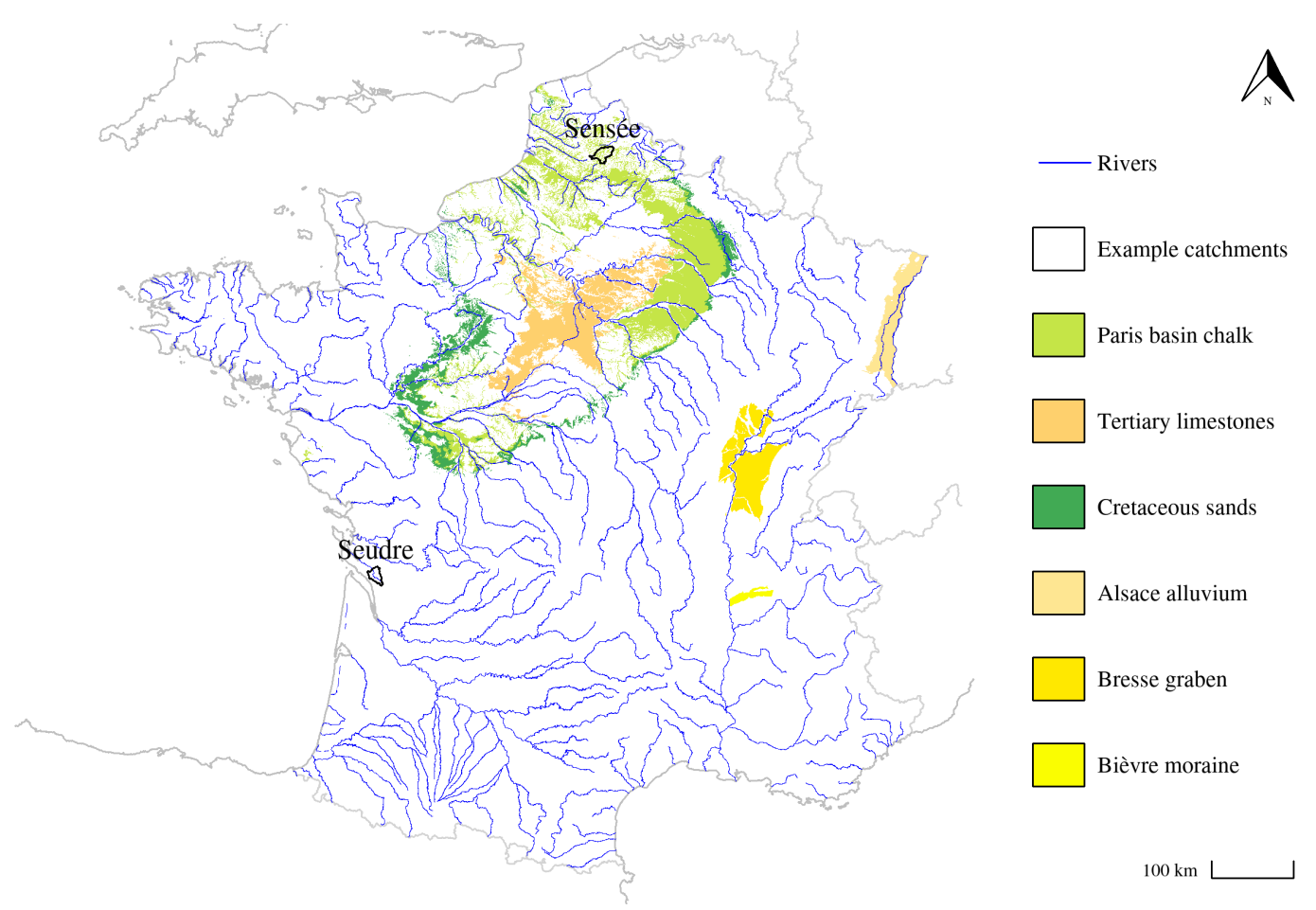

Figure 1. Outcropping areas of several major aquifers in mainland France and locations of example catchments shown in figure 2.

\subsection{Data sources}

Climatic data were taken from the SAFRAN re-analysis (Vidal et al., 2009) by Météo France; they are available at a daily time step for the 1958-2018 period. Daily potential evaporation was computed using the formula by Oudin et al. (2005). Streamflow data were retrieved from the French national database Banque Hydro (Leleu et al., 2014; SCHAPI, 2021). These hydroclimatic data are aggregated at the catchment scale and at a daily time step for mainland France in the HydroSafran database (Delaigue et al., 2021), maintained by INRAE.

Groundwater level data are from the French national database ADES (BRGM, 2021), which gathers piezometric data from many providers in the French territory. Selected piezometers were taken from two reference networks, to ensure the quality of data: RNESOUPMOBRGM - national quantitative monitoring network managed by BRGM, the French national geological survey - and RNESP - heritage national network for groundwater monitoring.

\subsection{Sample selection}

The French national reference cartography of hydrogeological formations BDLISA (Brugeron et al., 2018) was used to select a sample of catchments and for each catchment, one or several piezometers monitoring relevant aquifers were chosen. First, using the provided metadata, each piezometer extracted from the ADES database was associated with a hydrogeological entity 


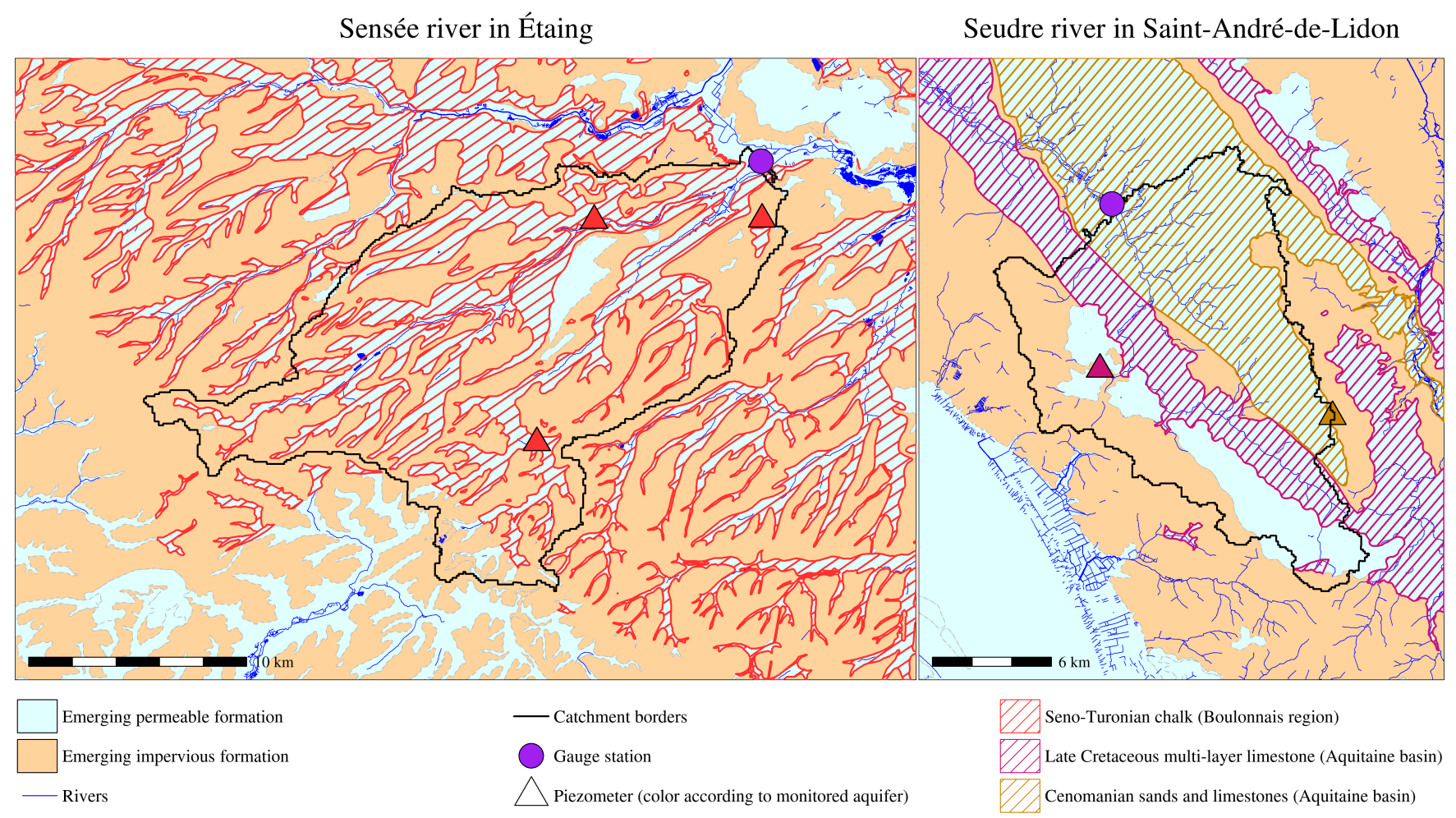

Figure 2. Two examples of hydrological maps of catchments used for sample selection. Their location in the French mainland territory is shown in figure 1.

in BDLISA, representing an aquifer. Catchments in which anthropic activities - dams, major direct withdrawals or inflows are known to have a significant influence on streamflow and catchments in which more than $10 \%$ of precipitations fall as snow were discarded. Then, for each catchment, piezometers associated with aquifers emerging inside the catchment boundaries were listed and maps - see an example in figure 2 - were produced to assess the relative importance of each hydrogeological formation for the catchment.

After this spatial selection, the available groundwater level and streamflow data were examined. An initial visual inspection of the time series was performed to eliminate data of too low quality. Then, catchments and piezometers were selected according to the following criteria :

- At least 20 years of continuously available streamflow data with less than $10 \%$ of missing data;

- At least 20 years of continuously available groundwater level data with less than $10 \%$ of missing data;

- At least 10 years of continuous contemporaneity between streamflow and groundwater level. 
Figure 2 shows two situations encountered at this stage: on the left, the Sensée catchment is connected to one monitored aquifer but three piezometers are available. In this case, the piezometer with the longest time series, with respect to contemporaneity with streamflow data, was selected to represent the aquifer. On the right, the Seudre catchment is connected to two monitored aquifers with one piezometer for each one; in that case, the two piezometers are kept. The choice of keeping only one piezometer per aquifer in the catchment was made for the sake of simplicity; in most catchments, when comparing the dynamics of the groundwater level time series, no major difference was encountered between piezometers monitoring the same aquifer within the same catchment.

Table 1. Geographical characteristics of the 107 catchments dataset

\begin{tabular}{rrrrr}
\hline & Surface $\left(\mathbf{k m}^{2}\right)$ & Outlet altitude $(\mathbf{m})$ & Mean altitude $(\mathbf{m})$ & Maximum altitude $(\mathbf{m})$ \\
\hline Minimum & 27.0 & 0 & 39 & 65 \\
1 st quarter & 168.2 & 27 & 113 & 169 \\
Median & 326.0 & 62 & 136 & 236 \\
Mean & 617.0 & 81 & 175 & 236 \\
3rd quarter & 685.7 & 114 & 202 & 330 \\
Maximum & 7,907 & 367 & 667 & 1421 \\
\hline
\end{tabular}

Table 2. Hydrological characteristics of the catchment dataset. The aridity index is defined as the quotient of annual rainfall and annual PET.

\begin{tabular}{rrrrrrr}
\hline & $\begin{array}{l}\text { Mean annual } \\
\text { streamflow (mm) }\end{array}$ & $\begin{array}{l}\text { Mean annual } \\
\text { rainfall }(\mathbf{m m})\end{array}$ & $\begin{array}{l}\text { Mean annual } \\
\text { potential evaporation }(\mathbf{m m})\end{array}$ & $\begin{array}{l}\text { Catchment } \\
\text { yield (\%) }\end{array}$ & $\begin{array}{l}\text { Aridity } \\
\text { index }\end{array}$ \\
\hline Minimum & 29 & 626 & 600 & 4.6 & 0.90 \\
1st quarter & 146 & 723 & 638 & 21 & 1.09 \\
Median & 210 & 808 & 658 & 27 & 1.18 \\
Mean & 238 & 828 & 667 & 28 & 1.25 \\
3 rd quarter & 316 & 921 & 693 & 34 & 1.40 \\
Maximum & 795 & 1,413 & 792 & 56 & 2.35 \\
\hline
\end{tabular}

Finally, this selection process yielded to a sample of 107 catchments and 160 piezometer/catchment couples. The majority of catchments - 73 - are associated with only one piezometer; 22 of them with two; eight of them with three; one of them with four and three of them with five piezometers. Tables 1 and 2 show some characteristics of the sample. The necessity to choose catchments which are not under significant anthropic influence led to a selection mainly composed of small headwater catchments, representative of the climatic diversity of the French territory. Dismissing the mountainous catchments to avoid 


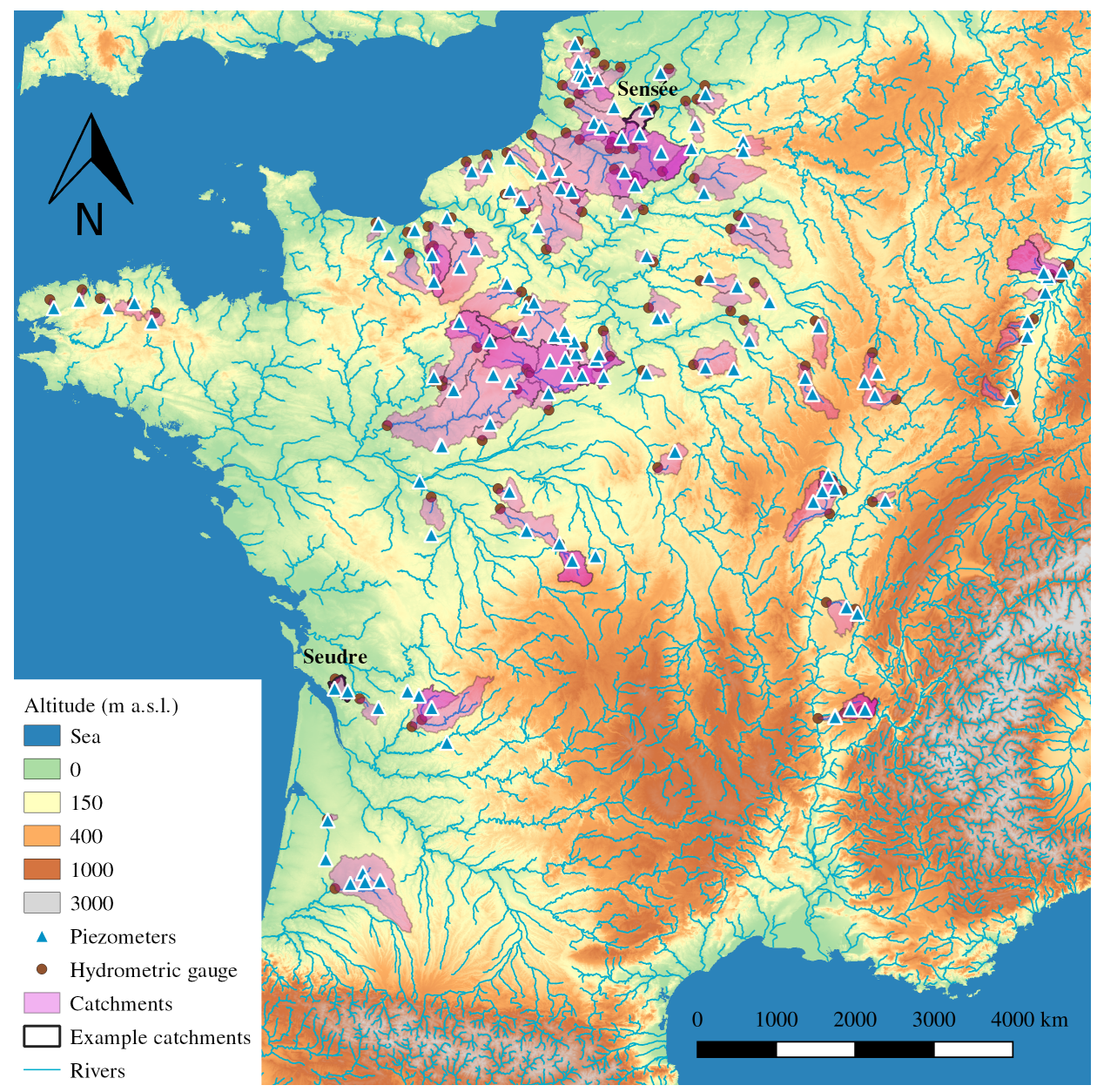

Figure 3. Map of the catchment and piezometer dataset. Example catchments of figure 2 are shown.

the influence of snow favoured the selection of lowland catchments, although several Vosges catchments, whose downstream part is linked to the Alsace plain aquifer, reach maximum altitudes above 1,000 $\mathrm{m}$.

Figure 3 shows a map of the selected catchments and piezometers. The northern part of mainland France, especially the Paris basin, is over-represented because of data availability; in particular, the chalk and tertiary limestone aquifers in this basin are the hydrogeological formations that have been monitored for the longest time in the territory. However, attention was paid to represent the diversity of hydrogeological contexts, with smaller local aquifers or fractured bedrock aquifers, in order to assess the proposed modelling approach in the widest possible range of configurations. 
https://doi.org/10.5194/hess-2021-413

Preprint. Discussion started: 16 August 2021

(c) Author(s) 2021. CC BY 4.0 License.

\subsection{Presentation of the original GR6J model}

\subsubsection{General presentation}

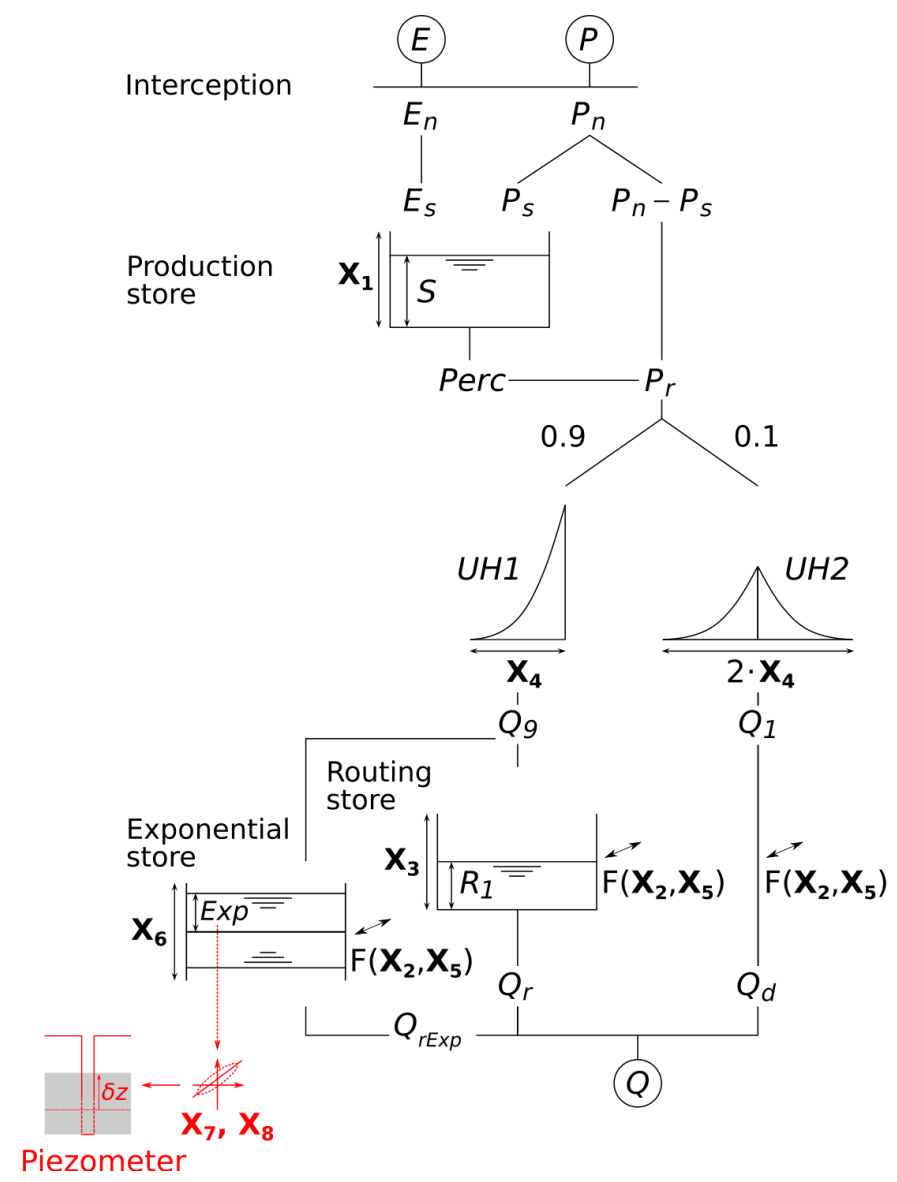

Figure 4. Structure of the original GR6J model - in black - and built-in piezometry simulation module - in red. See table C for the meaning of parameters and variables.

GR6J - for modèle du Génie Rural à 6 paramètres Journalier - is a daily six-parameter rainfall-runoff model. It was developed by Pushpalatha et al. (2011), as an evolution of previous GR4J (Perrin et al., 2003) and GR5J (Le Moine, 2008) versions, using a conceptual description of the hydrological processes taking place in the catchment: the model structure, visible in black in figure 4, is composed of stores, unit hydrographs and empirical equations that link them. The model is lumped and operates at a daily time step, taking as inputs precipitation and potential evaporation, averaged on the time step 
and the spatial extent of the catchment. GR6J is also parametric, i.e. for each catchment, 6 independent parameters have to be identified. All variables and parameters are expressed either as water depth, in millimetres, or are unitless.

This section does not intend to report the modelling tests that led to the development of the GR6J structure, since the original paper by Michel (1983) - such discussions can be found in Perrin et al. (2003), Le Moine (2008) or Pushpalatha et al. (2011). A summary description of the model computations is available in appendix A; a table of variables is available in appendix C. Computing codes can be found in the open-source airGR package (Coron et al., 2017, 2021) available for the R language (Slater et al., 2019; R Core Team, 2021).

This version does not take into account solid precipitations. A snow module, CemaNeige, has been developed by Valéry et al. $(2014 \mathrm{a}, \mathrm{b})$, but it is out of the scope of this study, which is limited to catchments with less than $10 \%$ of solid precipitations and where glaciers do not have an influence on streamflow.

\subsubsection{Parametrisation strategy}

For each catchment, the model is calibrated to fit measured streamflow: the six parameters are determined through an optimisation process, by minimising an error criterion between measured and simulated streamflow, in a reference period. Commonly used criteria are the Nash-Sutcliffe efficiency or NSE (Nash and Sutcliffe, 1970), the Kling-Gupta efficiency or KGE (Gupta et al., 2009; Kling et al., 2012) and the root mean square error (RMSE).

Since the six parameters have very different dimensions and variation ranges, each of them is transformed with a bijective function to fit into the $[-9.99 ; 9.99]$ interval. Thereby, the optimisation space for optimal parameter research becomes

$[-9.99 ; 9.99]^{6}$, which helps most optimisation algorithms find the global optimum. Detailed transformations and ranges are available in appendix B. Several optimisation algorithms are used to calibrate the GR6J model, examples can be found in Coron et al. (2021).

\subsection{Study of the model correlation with piezometry}

To adapt the existing model structure for groundwater level simulation, we followed a approach similar to other lumped conceptual models, i.e. using a store as a representation of the aquifer, regarding the water content in the store as groundwater level. With this aim in mind, a correlation study was performed on the dataset presented in section 2, in order to identify which of the three conceptual reservoirs of the model structure was the most correlated with piezometry.

GR6J was calibrated for the 107 catchments of the dataset using the Nash-Sutcliffe efficiency criterion computed on the square root of streamflow. Then, the time series of model states obtained - the levels of the three conceptual stores and simulated streamflow as control data - and the groundwater level time series were aggregated at a monthly time step, to avoid problems caused by missing piezometry measurements. Afterwards, for each of the 160 catchment/piezometer couples, Spearman's correlation (Spearman, 1907) between piezometry and each state series was computed; the results are summarised as boxplots in figure 5. The exponential store - see figure 4 for a description of the model - is the most correlated with piezometry and, moreover, it is the only store to be more correlated with groundwater level than with streamflow. The median correlation obtained is 0.762 and $80 \%$ of couples reach a value higher than 0.5 . 


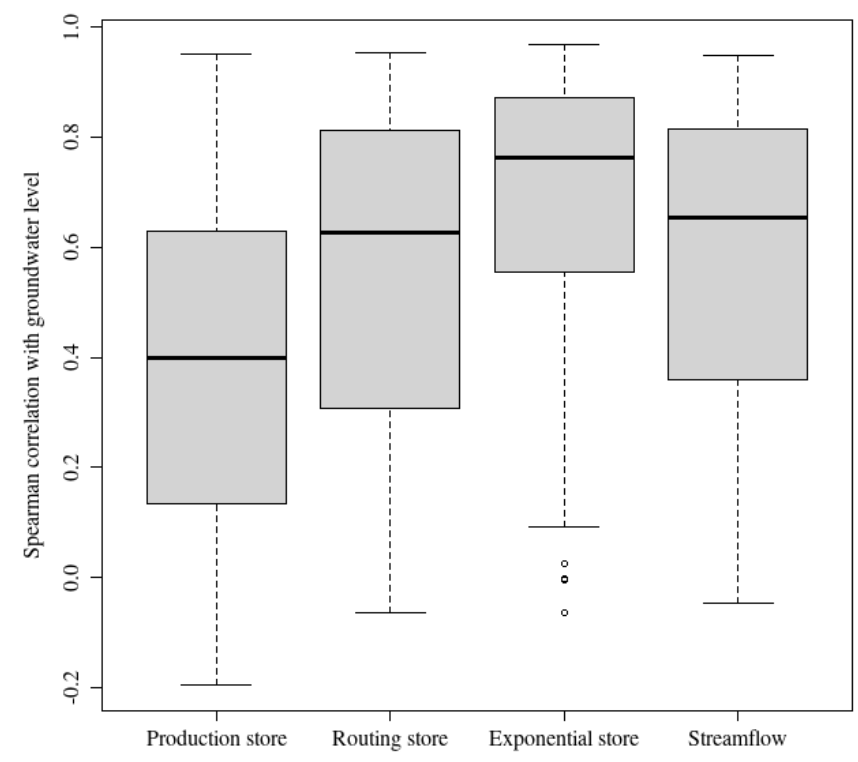

Figure 5. Distributions of correlations between piezometry and several states of the model

A high Spearman correlation may highlight a non-linear relationship, since it is a rank correlation. However, it does not seem to be the case here: other investigations not detailed here show that the relationship between the exponential store content and the groundwater level can be regarded as linear, all the more so as the correlation is high. Therefore, it was decided to use the exponential store to simulate piezometry, with an adapted scheme presented in the following section.

\subsection{Adaptation of the model scheme}

A built-in module is added to the existing model structure to simulate groundwater level. The streamflow simulation chain is not modified, but a new output is added to the model, through a linear transformation of the exponential store level.

Groundwater level absolute values strongly depend on the piezometer location - its altitude, but also its position with respect to the catchment topography. Indeed, two piezometers monitoring the same aquifer and therefore representing the same dynamics can have different mean levels and their fluctuations can have different ranges - for instance, if the first one is located on a plateau while the second one is on a slope. To avoid having to take into account these problems, it was decided to work with piezometric relative anomalies $\delta z$, where $\bar{z}$ is the mean of piezometric time series and $\sigma_{z}$ its standard deviation:

$\delta z=\frac{z-\bar{z}}{\sigma_{z}}$ 
Then, two additional parameters $X_{7}$ and $X_{8}$ are added to the model to represent the relationship between the exponential

$\delta_{z, \operatorname{sim}}=\frac{1}{X_{7}}\left(\frac{\operatorname{Exp}}{X_{6}}+X_{8}\right)$

Simulated piezometry $z_{\text {sim }}$ can be computed by reversing equation 1 :

$z_{\text {sim }}=\sigma_{z} \delta_{z, s i m}+\bar{z}$

$X_{7}$ is the groundwater linear coefficient; trials have shown that it generally takes values between 0 and 1 but can reach 4 . $X_{8}$ is called the groundwater linear offset and takes non-negative values, with an upper bound at 20 . The new built-in module is shown in red in figure 4.

\subsection{Composite calibration strategy}

Now that two additional parameters have been added to the model structure to simulate piezometry, it is necessary to determine their value through an adapted parametrisation strategy. A composite objective function is chosen for calibration, using a linear combination of a criterion on streamflow - the Nash-Sutcliffe efficiency computed on the square root of streamflow - and a criterion on piezometry, called ZError and defined as:

ZError $=1-\sum_{t}\left(\delta_{z, \text { sim }}(t)-\delta_{z, o b s}(t)\right)^{2}$

Removing the anomaly formulation, we can see that ZError is in fact Nash-Sutcliffe efficiency for piezometry:

ZError $=1-\frac{\sum_{t}\left(z_{s i m}-z_{o b s}\right)^{2}}{\sum_{t}\left(z_{o b s}-\bar{z}\right)^{2}}$

Since the two criteria on streamflow and piezometry have the same variation ranges -$]-\infty ; 1]$ - and the same properties, the objective function $C$ for composite calibration can be taken as a linear combination of the two criteria, with a weight $\alpha$ :

$C(\alpha)=\alpha$ ZEror $+(1-\alpha) N S E$

$\alpha$ can take any value between 0 and 1: $\alpha=0$ means that the calibration is performed only on streamflow and $\alpha=1$ only on piezometry. In order to find a compromise between these two objectives, 51 values are explored from 0 to 1 by a step of 0.02 . For each value of $\alpha, C(\alpha)$ is maximised as a function of eight parameters. The parameter space transformations described in appendix B are used to convert the optimisation space into the hypercube $[-9.99 ; 9.99]^{8}$. The differential evolution global 
optimisation algorithm - implemented in the RcppDE R package (Price et al., 2006; Mullen et al., 2011; Ardia et al., 2011a, b; Eddelbuettel, 2018; Slater et al., 2019; Ardia et al., 2020; R Core Team, 2021) - is then executed to find the global optimal point for the eight parameters.

\subsection{Split-sample test evaluation scheme}

To assess the effect on streamflow simulation of the new calibration scheme described above, a split-sample test (Klemeš, 1986) is conducted for each catchment/piezometer couple of the assessment dataset described in section 2. For each couple, the available data are divided into two time periods $P_{1}$ and $P_{2}$ of equal length, defined so as to encompass the same number of data points for which both groundwater level and streamflow are available. Thereby, both periods contain the same amount of information and can be equally used for calibration and validation. Before each period, a warm-up timespan of 5 years is set: the model is run on this period but the resulting simulated values are not used to compute criteria.

After determining these periods, the adapted model structure is calibrated on $P_{1}$ using $C(\alpha)$, for each value of $\alpha$; the parameter set obtained is then used to run the model on $P_{2}$ and compute several validation criteria. Then, the periods are switched and the same procedure is executed. The following validation criteria are used:

- NSE $(\sqrt{Q})$ to evaluate the model performance on the whole streamflow spectrum;

- $N S E(\sqrt[3]{Q})$ to evaluate the model performance on low-flows. It was preferred to zero-diverging transformations such as $\frac{1}{Q}$ or $\log (Q)$ to avoid numerical problems with very low streamflow values;

- ZError to assess the model performance in groundwater level simulation.

Since the evaluation is performed for validation, the results presented in section 4 are, unless otherwise specified, validation results.

\section{Results and discussion}

\subsection{Is low-flow simulation improved?}

Model performance for streamflow simulation in validation is not improved by the proposed calibration scheme. Figure 6 shows that the distribution of Nash-Sutcliffe efficiency computed on the square root of streamflow does not appear to change significantly for values of $\alpha$ under 0.34 ; for higher values, the performances deteriorate, but it is surprising to note that they slowly decrease while increasing $\alpha$ and they remain acceptable until $\alpha=0.84-$ even though the loss of about 0.2 is significant. Beyond these values, the performances have considerably deteriorated: the calibration cannot be suitably performed on groundwater level time series only; this is an expected result, since the dynamics of groundwater level and streamflow signal are different. The same trend is observed with performances in low flows, assessed through Nash-Sutcliffe efficiency computed on the cubic root of streamflow. 

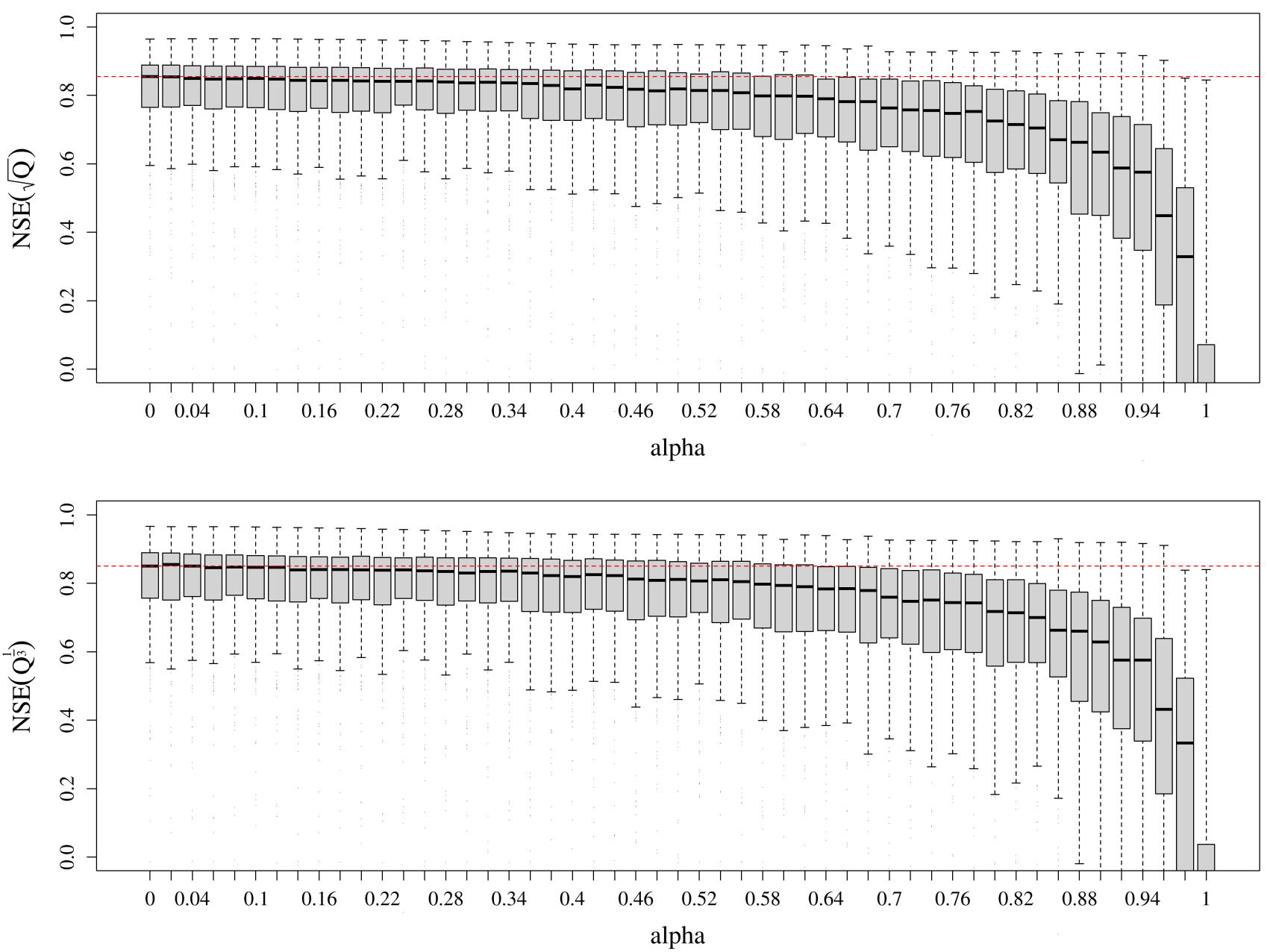

Figure 6. Distributions of the NSE criterion values, obtained in validation by the modified model on the 107 catchments, for the 51 values of $\alpha$, the criterion weight. The red dashed line indicates the median NSE value for the original calibration strategy $\alpha=0$.

\subsection{Is the model able to simulate groundwater levels?}

The model appears to be able to simulate groundwater levels with a satisfactory performance. Figure 7 shows the distributions of the ZError criterion for the 51 values of $\alpha$, compared to the theoretically maximum possible performance which is obtained with $\alpha=1$ - i.e. a calibration performed only on groundwater level with no streamflow information. The distribution of ZError values appears to be similar for all $\alpha$ values above 0.34, with a median ZError around 0.70. For $\alpha$ between 0.12 and 0.34 , the performance decreases slightly but remains close to the best possible performance, with median ZError around 0.66. Finally, for $\alpha$ under 0.1 , with very little groundwater level information added to the calibration process, the performance is much lower, but even for $\alpha=0.02$, it is acceptable, with a median ZError around 0.5 . 


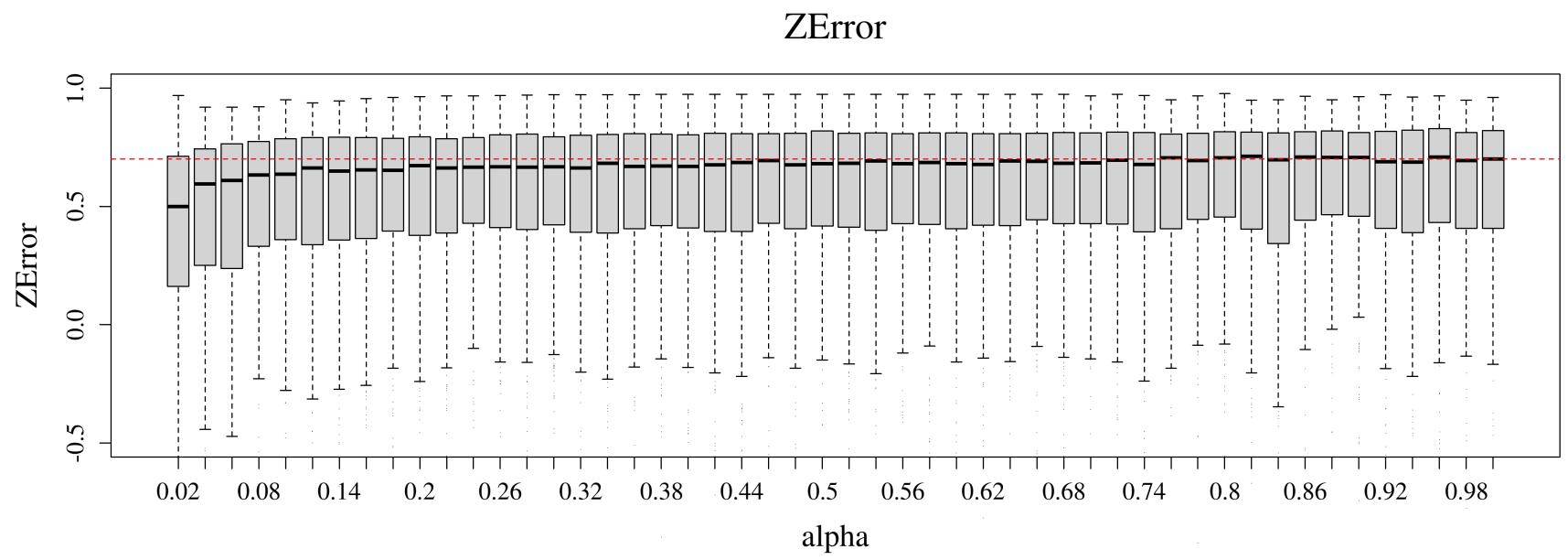

Figure 7. Distributions of the ZError criterion values obtained, for 50 values of $\alpha$, the criterion weight. $\alpha=0$ was discarded since no groundwater level simulation is performed in that case. The red dashed line indicates the median ZError value obtained with $\alpha=1$, i.e. a calibration only on groundwater level.

\subsection{Recommended calibration framework and examples}

In order to objectify the differences between evaluation criteria distributions which were noted above, a Wilcoxon-MannWhitney test (Wilcoxon, 1945; Mann and Whitney, 1947; Bauer, 1972) was conducted. The distributions obtained for the values of $\alpha$ were compared with the reference ones: $\alpha=0$, i.e. the original calibration strategy, for NSE; $\alpha=1$, i.e. the theoretically most favourable situation for ZError. Therefore, for each value of $\alpha$, two tests are conducted: one to assess whether the streamflow simulation performance has significantly deteriorated and one to evaluate whether the performance of groundwater level simulation is significantly lower than the one obtained for $\alpha=1$. Results are presented as p-values in figure 8 , with a significance threshold of $5 \%$.

It appears that for values of $\alpha$ greater than 0.22 , streamflow simulation performance has significantly deteriorated; for $\alpha$ lower than 0.12, groundwater level simulation performance is significantly below that obtained for higher values of $\alpha$. A narrow interval $-\alpha$ between 0.14 and 0.2 - corresponds to values for which the model performance for both outputs is comparable to reference distributions: the model is as good at streamflow simulation as the original model and it cannot be better at groundwater level simulation. Therefore, it was decided to choose the value $\alpha=0.16$ as the recommended calibration framework, even though any value in the described interval could be chosen without significantly changing the results.

Figures 9 and 10 present an example of the new calibration framework applied to the Sensée catchment in Étaing, in the north of mainland France. The Sensée River is a tributary of the Scheldt, which is influenced by the Seno-Turonian chalk aquifer - see figure 2. This catchment is an outlier with respect to the model performance distribution, since Nash-Sutcliffe efficiency is improved by 0.14 for the period shown in the figures. However, this large difference is difficult to visualise, since 


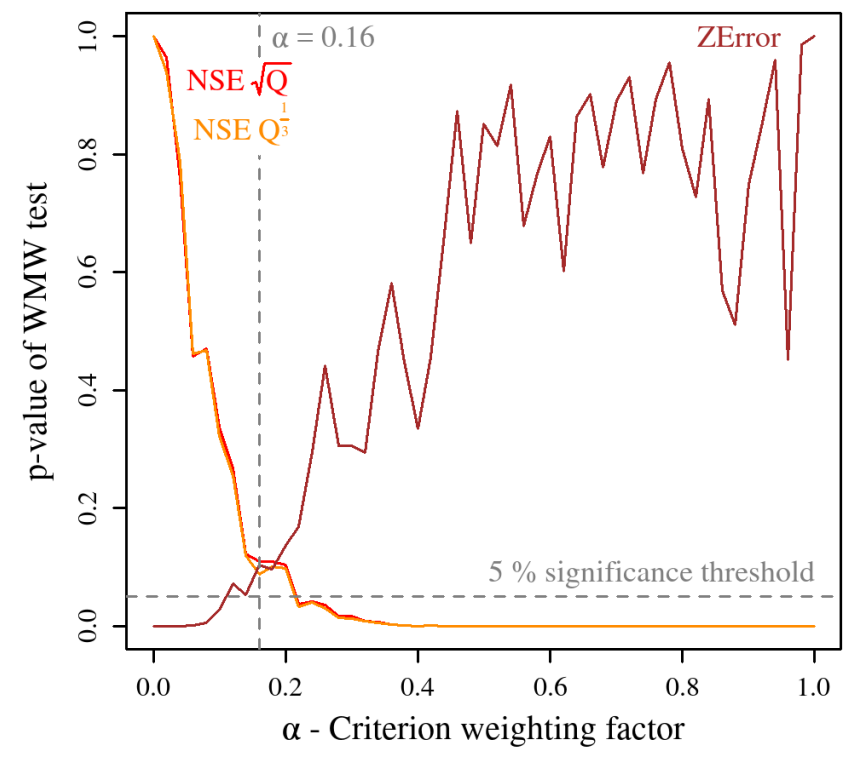

Figure 8. p-values of the Wilcoxon-Mann-Whitney tests comparing the criteria value distributions obtained for the 51 values of $\alpha$ with reference ones.

\section{The Sensée river in Etaing}

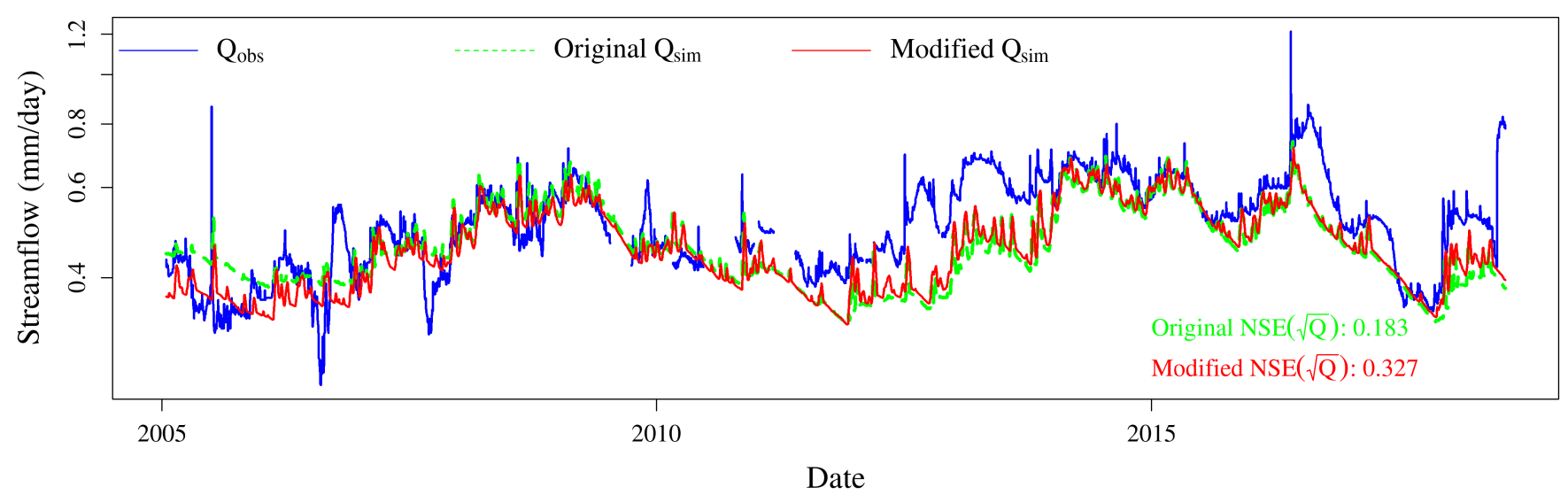

Figure 9. Observed and simulated streamflow of the Sensée River in Étaing, obtained with the original and the new calibration frameworks. Log-scale is used to focus on low flows.

the two simulated hydrographs are close. The ZError obtained is average - 0.630 - and multiyear groundwater dynamics are reproduced, but the model struggles to simulate the peaks of the observed piezometry time series. 


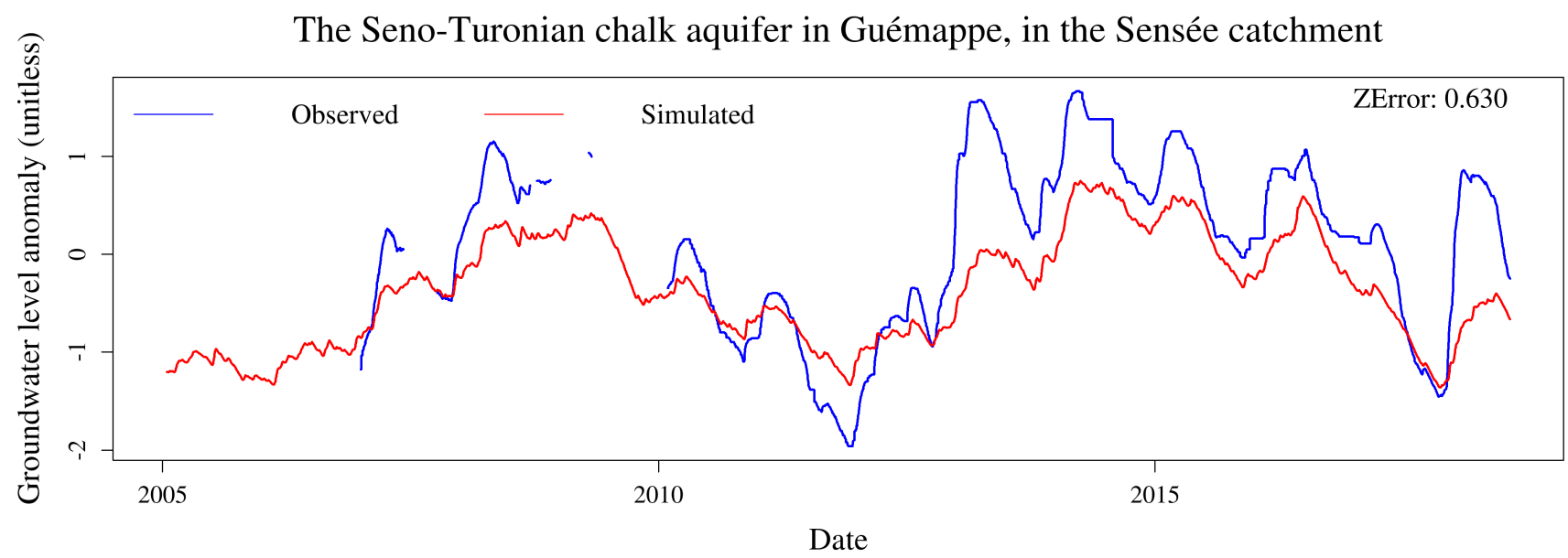

Figure 10. Observed and simulated groundwater level in the Sensée catchment, obtained with the new calibration framework.

The Seudre river in Saint-André-de-Lidon

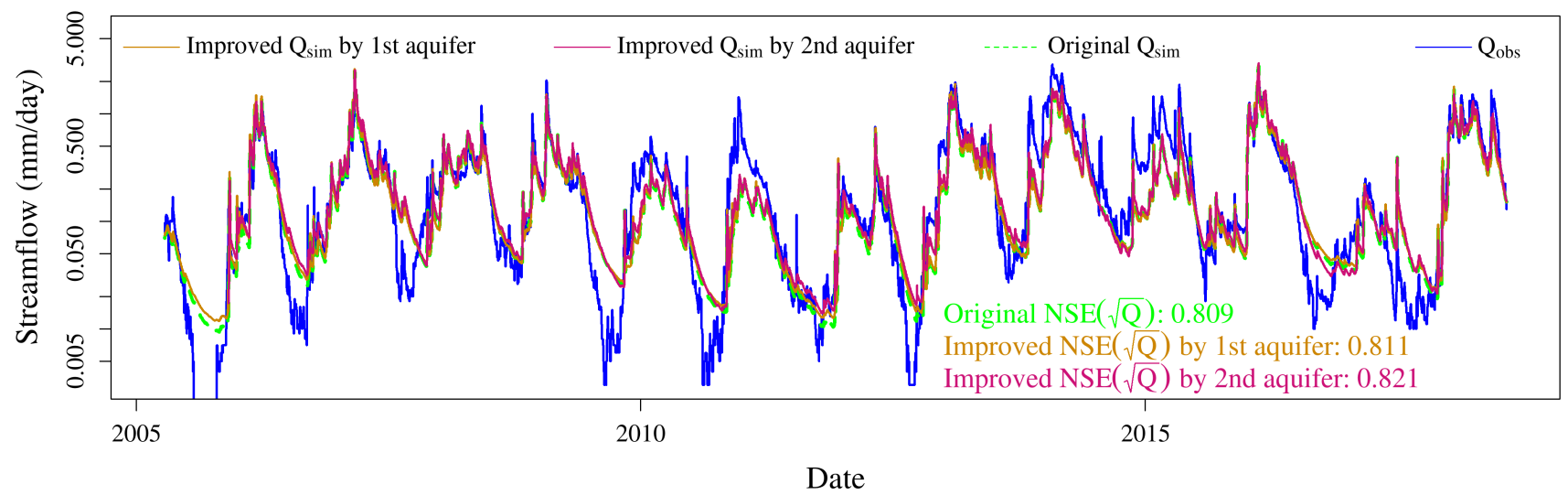

Figure 11. Observed and simulated streamflow of the Seudre River in Saint-André-de-Lidon, obtained with the original and the new calibration frameworks, for the two selected piezometers in the catchment. Log-scale is used to focus on low flows.

Another example catchment is presented in figures 11, 12 and 13: the Seudre River in Saint-André-de-Lidon. It is a small coastal river located in Saintonge, linked to two regional aquifers of the Aquitaine basin - see figure 2: the Cenomanian sands and limestones and the Late Cretaceous multi-layer limestones, each one being monitored by one selected piezometer. Figure 11 shows the results on streamflow: adding piezometry to the calibration process did not significantly improve the performance and the simulated hydrographs are not distinguishable. However, the results for groundwater simulation shown in figures 12 and 13 are satisfactory, with respective ZError values of 0.734 for Cenomanian sands and limestones and 0.787 for Late Cretaceous limestone. In addition, the main failure period for groundwater level simulation - between 2010 and 2012 - in 


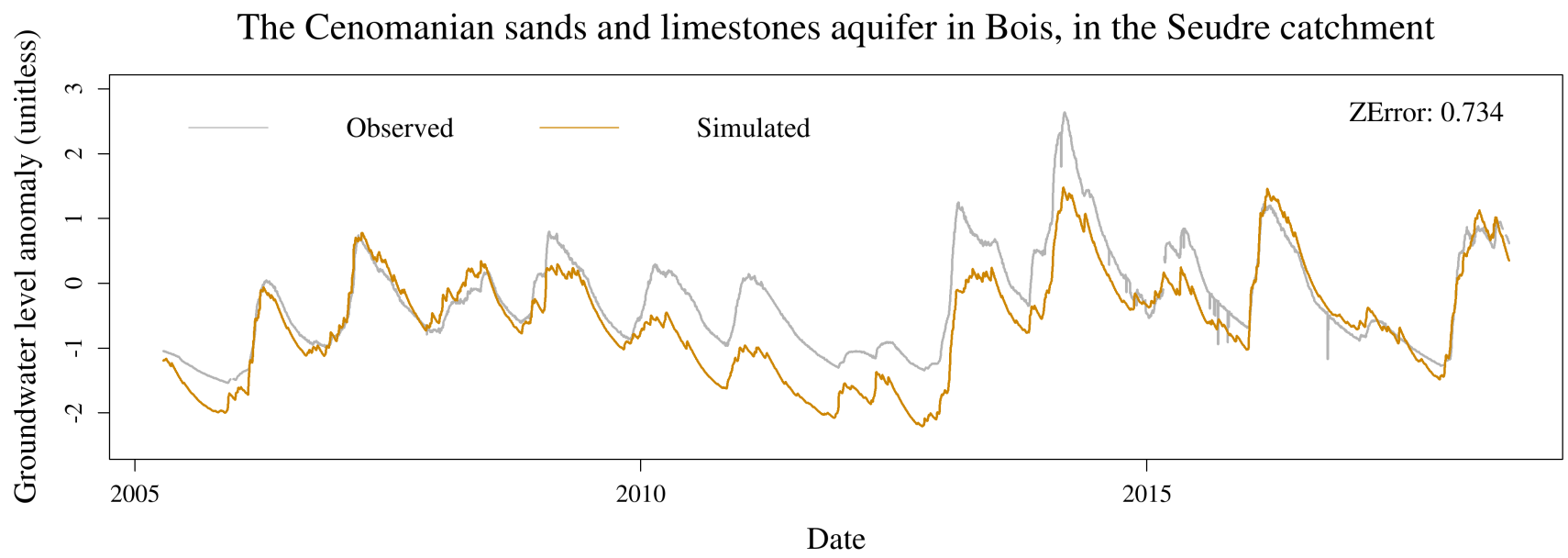

Figure 12. Observed and simulated groundwater level in the Seudre catchment, obtained with the new calibration framework: first piezometer.

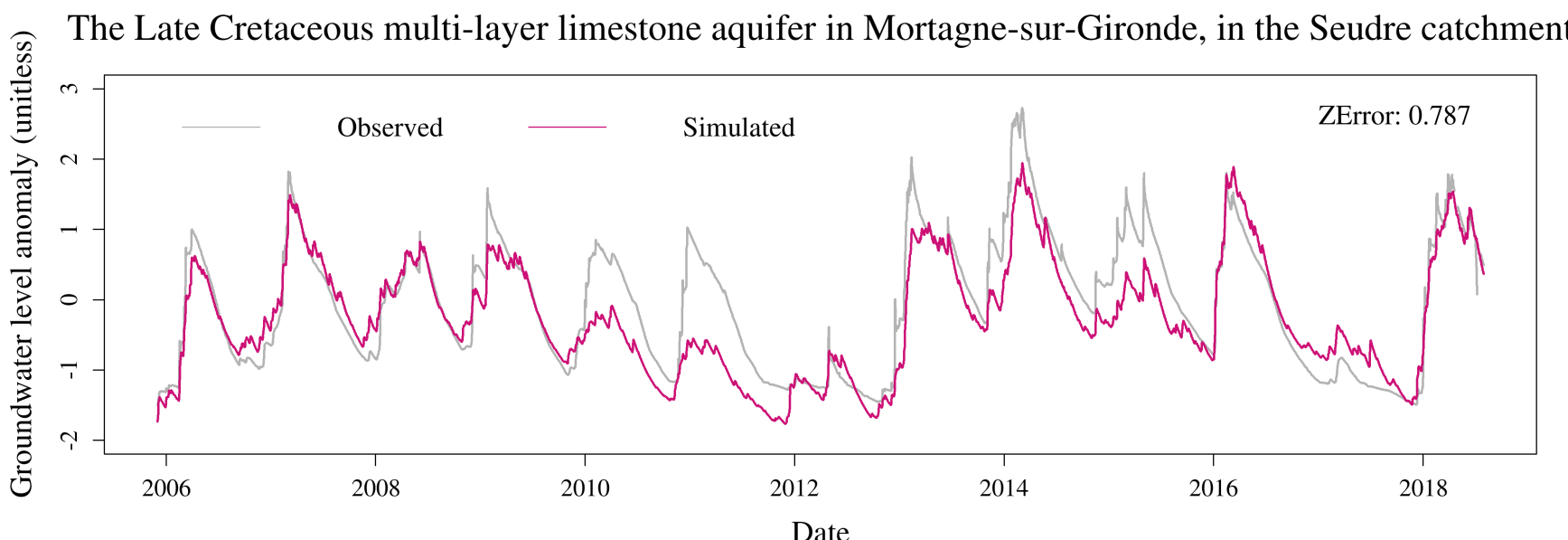

Figure 13. Observed and simulated groundwater level in the Seudre catchment, obtained with the new calibration framework: second piezometer.

which piezometry in underestimated, is also unsatisfactory for streamflow simulation, since the model is unable to reproduce the whole variability of the hydrograph during this period.

\subsection{Is the new parametrisation stable?}

The parametrisation stability between periods is another measure of the robustness of the model: if the parameter values depend on the calibration period, it will cast doubt on the model capacity to extrapolate streamflow values outside this period and thus, to be used, for instance, as a forecasting tool. The split-sample test allows us to assess this stability by comparing the parameter values between the two calibration periods $P_{1}$ and $P_{2}$. Figure 14 shows the results of this comparison for the six parameters 

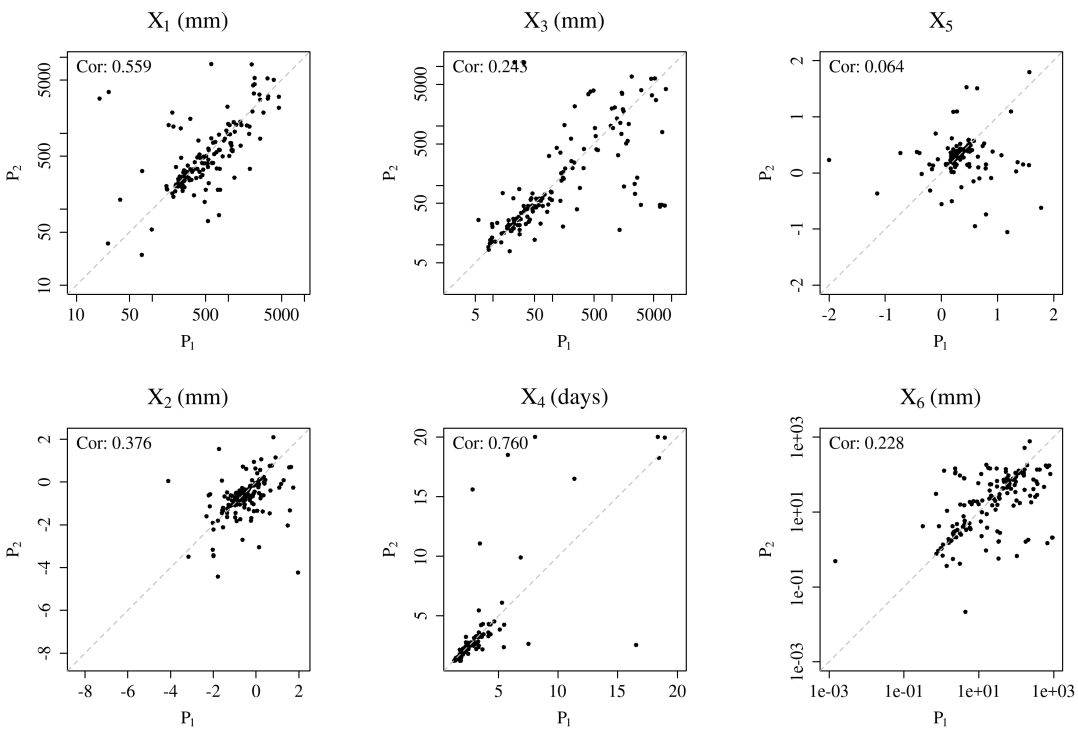

Figure 14. Comparison of the values obtained for the six model parameters through calibration on the two periods of the split-sample test, with the original calibration framework $-\alpha=0$. Log-scale is used for visual readability of some plots. Pearson correlation between periods is indicated.
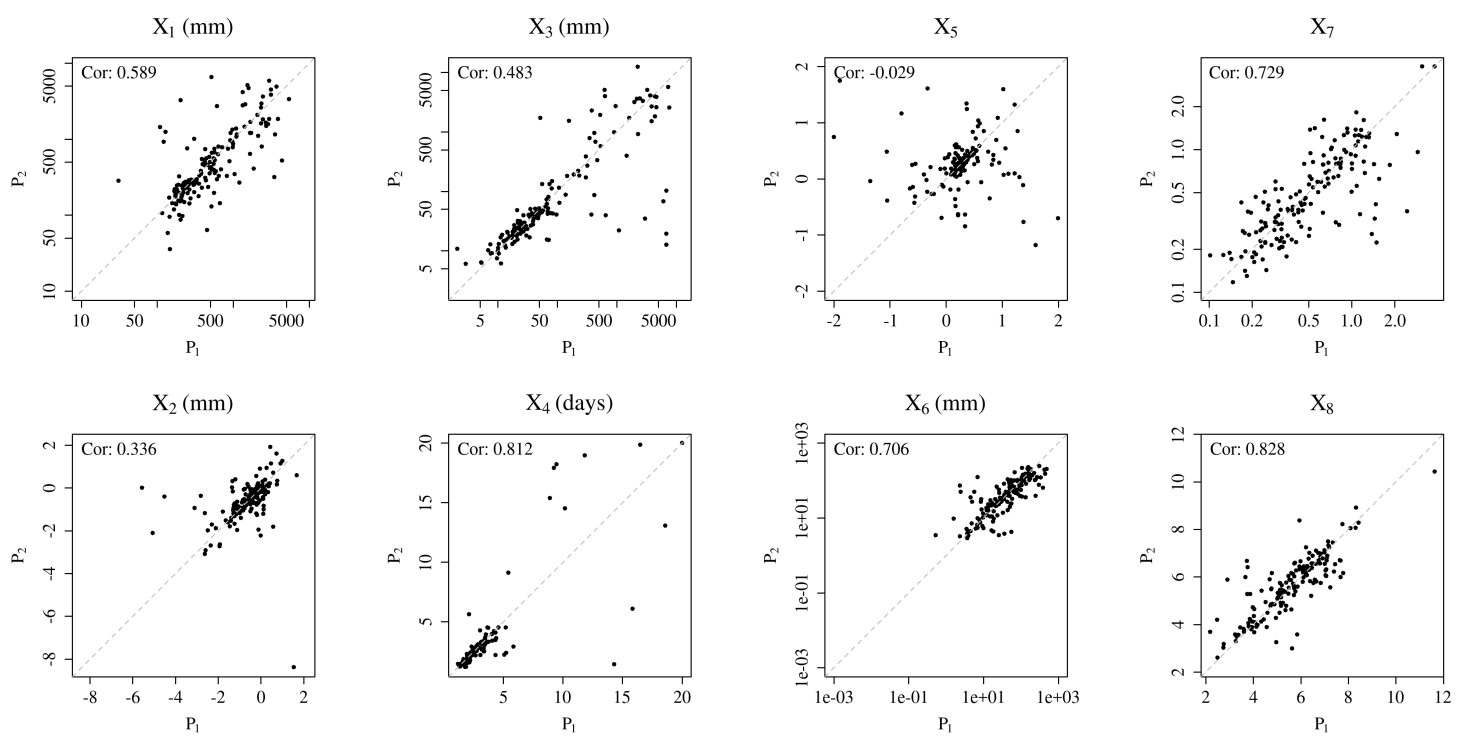

Figure 15. Comparison of the values obtained for the eight model parameters through calibration on the two periods of the split-sample test, with the composite calibration framework $-\alpha=0.16$. Log-scale is used for visual readability of some plots. Pearson correlation between periods is indicated. 
of GR6J and the original calibration framework - obtained with $\alpha=0$; figure 15 does so for the modified calibration, with the two added parameters. For each parameter, the Pearson correlation between the values obtained for the two periods was computed.

The original calibration framework leads to a rather stable parametrisation, except for the exchange threshold $X_{5}$ with a non-significant correlation between the two periods. The modified calibration, using groundwater level data, yields more stable parameter values, with increased correlations between the two periods, except for the two parameters ruling the inter-catchment exchange function, $X_{2}$ and $X_{5}$, for which the correlations have slightly deteriorated. The two added parameters, $X_{7}$ and $X_{8}$, are also very stable between periods, with a correlation of 0.73 . Since the modified calibration framework is a new constraint on the routing function, it is not surprising to note that the three routing parameters $-X_{3}, X_{4}$ and $X_{6}-$ become significantly more stable between periods, which is a sign of an improved model robustness.

The difficult transferability of the exchange function parameter values was highlighted by de Lavenne et al. (2016). Although this function is sometimes regarded either as the result of fluxes between topographic catchment - for instance, in karstic contexts, see e.g. Le Moine et al. (2008) - or as a representation between the catchment and an externalised aquifer, it is merely used by the model as a way to correct the global water budget. Poncelet (2016) underlined the relatively marginal role of the exchange threshold $X_{5}$, introduced by Le Moine (2008), in the general performance of the model. The stability issues exposed by the present study highlight the need for further development of this exchange function to take into account the henceforth explicit representation of groundwater level through the exponential reservoir.

\subsection{Is performance dependent on the regional and (hydro)geological context?}

There is no direct spatial pattern in the results shown in figure 16. Since the streamflow simulation performance differences between the original and the composite calibration frameworks are weak - and non-significant - the geographical distributions of their performance are similar. High scores are noted in the Aquitaine basin, in Brittany, in Upper Champagne and for the downstream tributaries of the Loire River - Maine and Indre basins. Lower values of NSE are found in the Beauce plain, in the Somme basin, in the inland part of the North region - mostly in the Scheldt basin - and in the Saone and Rhone basin, with the particular case of the Bièvre morainic plain in which the minimum performance is reached. Other parts of the Paris basin, the North Sea coastal rivers and the Alsace plain have a mixed situation but generally do not reach the extreme points of the NSE distributions.

Catchments in which the performance gain between the two calibration frameworks is significant, i.e. beyond 0.05 , are all located either on the Picardy and Normandy chalk or in the Beauce plain. It is interesting to note this significant improvement is observed in catchments in which the initial model performances was low. However, these areas also host catchments for which the composite calibration framework produces a significant deterioration of streamflow simulation performance.

As for the groundwater level simulation, the performance does not follow the same spatial distribution as streamflow. High ZError values are observed in Brittany and in the western part of the Paris basin, along a crescent running from Artois to

415 Touraine. Lower scores are reached in the Bièvre plain, in Upper Champagne and in the extreme south of Paris basin on the Massif Central piedmont. Other regions have mixed results with no clear spatial pattern. 
$\operatorname{NSE}(\sqrt{\mathrm{Q}})$ for original calibration

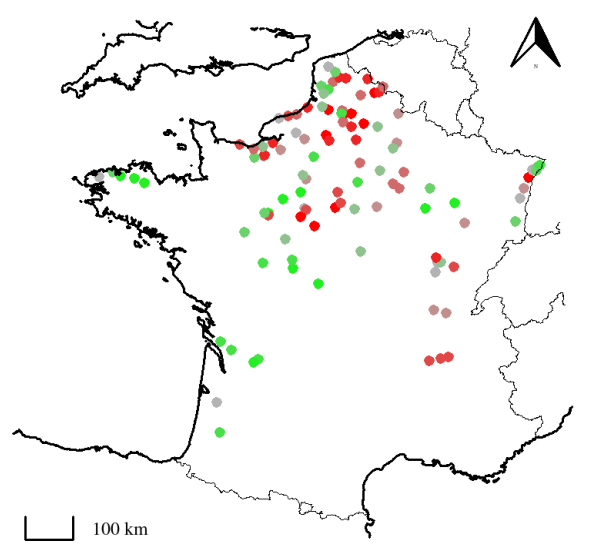

\section{ZError}

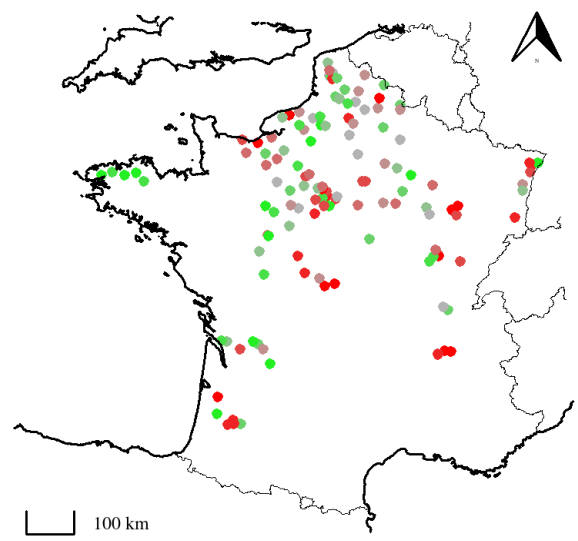

$\operatorname{NSE}(\sqrt{\mathrm{Q}})$ for composite calibration

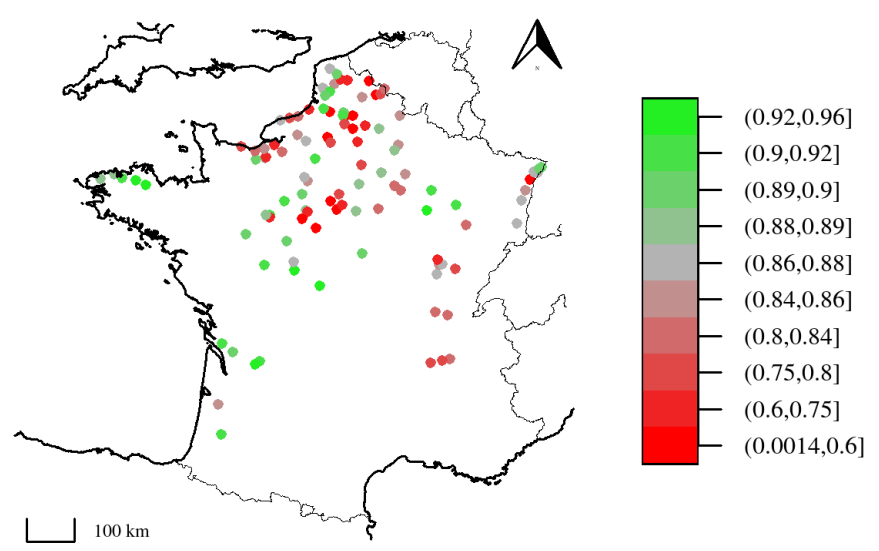

$\Delta \operatorname{NSE}(\sqrt{\mathrm{Q}})$ between calibrations

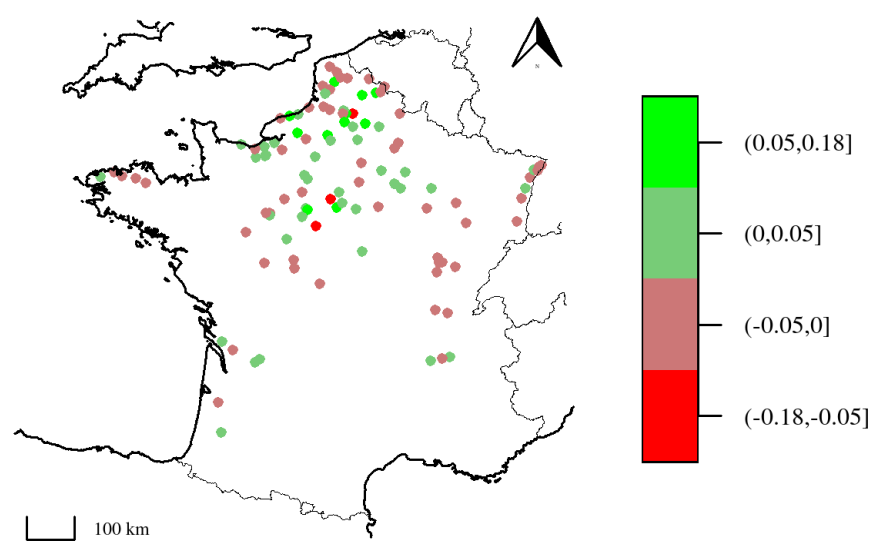

Figure 16. Map of the results. From top-left to bottom-right: value of the Nash-Sutcliffe efficiency at each gauge station, computed on the squareroot of streamflow, for the original calibration, i.e. $\alpha=0$; value of the Nash-Sutcliffe efficiency at each gauge station, computed on the square root of streamflow, for the composite calibration, with $\alpha=0.16$; value of the ZError criterion at each piezometer, for $\alpha=0.16$; difference between NSE obtained with the composite and the original calibration frameworks. For each point, the maximum value among catchment/piezometer couples was chosen.

To assess the influence of the geological context, the test dataset of 160 catchment/piezometer couples was divided into six groups, detailed in table 3. The groups were established in accordance with the hydrogeological formation attributed to each piezometer, in the BDLISA reference inventory by Brugeron et al. (2018). This classification may look arbitrary or inaccurate, 
since each piezometer corresponds to an idiosyncratic local situation; however, such a subgroup analysis of the test dataset highlights the influence of geology on the model performance, as seen in figure 17.

For the absolute streamflow simulation performance, the original calibration framework yields high values of NSE for groups 2, 4 and 6, medium ones for group 1 and lower scores for groups 3 and 5. These patterns are found again for the composite calibration framework, even though the distribution of performances for group 5 is narrower. Regarding the difference between the two calibration frameworks, a significant improvement for a small part of the sample is observed in groups 3 and 5 too, with no deterioration of the median performance in the group, while in groups 1, 2, 4 and 6, the median performance is reduced. A significant decrease in performance is observed for a quarter of group 2 and more than a decile of group 4. As for groundwater level simulation, groups 3, 4 and 6 have narrow distributions centred around a high median score - around 0.7 - while other groups have much wider distributions including simultaneously high, medium and low scores.

Table 3. Groups of catchment/piezometer couples, gathered by geological context

\begin{tabular}{lll}
\hline Number & Number of couples & Description \\
\hline 1 & 26 & Quaternary alluvia \\
2 & 11 & Bedrock and Triassic sandstones \\
3 & 72 & Chalk and Cretaceous limestones \\
4 & 20 & Paleogene and Neogene limestones \\
5 & 19 & Jurassic limestones \\
6 & 12 & Cretaceous sands \\
\hline
\end{tabular}

\subsection{Synthesis: which calibration should be used in which context?}

The analyses performed in the previous sections lead to the following recommendations for the model calibration:

- in most catchments, no improvement in streamflow simulation is expected using a composite calibration framework with groundwater level data;

- in catchments in which the original model already performs well, adding groundwater level data to the calibration is probably useless to improve streamflow simulation performance;

- in catchments in which the model reaches lower validation scores, a performance improvement is possible but not probable and it is most likely to happen in a chalk or tertiary limestone context;

- the model, with composite calibration, is able to simulate groundwater level with satisfactory performance for chalk, tertiary limestones and Cretaceous sand aquifers;

- groundwater level simulation is more uncertain for other geological contexts (quaternary formations, bedrock, Triassic sandstones or Jurassic limestones). Good results have been observed in the bedrock context of Brittany. 

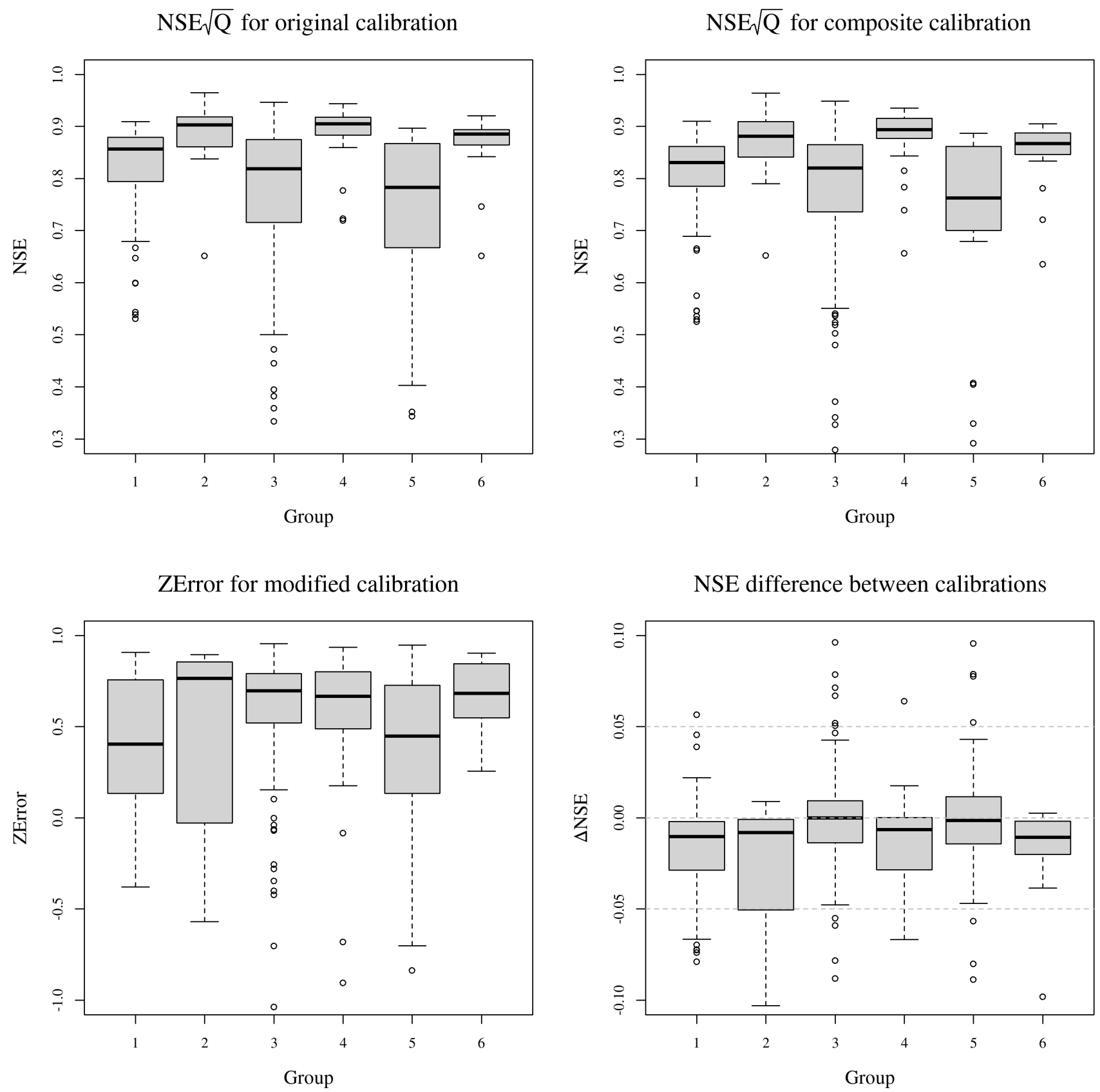

Figure 17. Distributions of results for groups detailed in table 3. From top-left to bottom-right: value of the Nash-Sutcliffe efficiency for each couple, computed on the square root of streamflow, for the original calibration, i.e. $\alpha=0$; value of the Nash-Sutcliffe efficiency for each couple, computed on the square root of streamflow, for the composite calibration, with $\alpha=0.16$; value of the ZError criterion for each couple, for $\alpha=0.16$; difference between NSE obtained with the composite and the original calibration frameworks. 


\section{Conclusions}

The study presented here concerns the implementation of a new calibration procedure for an existing streamflow simulation model, GR6J; it is not about the development of a completely new model. For each catchment, among all parameter sets that yield a similar value of the evaluation criterion, we identified a particular parameter set which is able to simulate, moreover, groundwater level. This new modelling capacity does not induce a significant deterioration in the streamflow simulation performance, neither does it improve it, except in a few particular cases. However, an advantage of the composite calibration framework was highlighted: since we identified a particular parameter set among equivalent sets for streamflow, we probably reduced equifinality in the model calibration, which is suggested by the parameter stability improvement. We may thus expect a more robust model.

Beyond streamflow simulation, being able to simulate groundwater level using such a lumped conceptual model - much simpler and lighter to implement than usual groundwater models - is likely to lead to new uses of GR6J. Thereby, since GR6J is part of the operational low-flow forecasting platform Premhyce (Nicolle et al., 2020; Tilmant et al., 2020), it is conceivable to use it as a groundwater level sub-seasonal forecasting tool in some chosen points in France, which is crucial for groundwater resource management anticipation. Further studies are needed to evaluate the framework in forecasting mode; a data assimilation process may be necessary to improve the forecast liability and smoothness. Although this study does not include any modification of the streamflow simulation scheme, it offers an overview of possible modifications: the division coefficient between the routing and the exponential stores remained fixed in the present study and may become a new model parameter to rule the size of the aquifer-river flux; the role of the exchange function needs to be clarified and its formulation has to become more stable and readable.

The results presented in this paper can be seen as truly encouraging - realistic representation of the piezometric variability as one of the states of the model - but scientific honesty requires us to mention that to us they were - at least initially truly disappointing, because we aimed at improving the overall representation of streamflow through inclusion of piezometric information and not the other way around. Of course, a question arises that we do not wish to avoid in this paper: is this disappointing conclusion model-specific, i.e. is it due to the conceptual nature of the GR6J model? Would a less conceptual and more descriptive model have yielded more satisfactory results? Would a more heavily parameterised model have yielded more satisfactory results? Let us first answer this second question: equifinality is a plague in all modelling efforts, and we would not claim as a success an operation that would consist in improving marginally the situation of a model that was previously impossible to calibrate. Thus, we reject the critique on model complexity as unworthy for a modeller. Concerning the physical realism of the model, we can accept the critique. But we would counter the critique in that the fact that the exponential reservoir - introduced in GR6J structure to represent the slow aquifer transfers - represents either well or very well the dynamics of piezometers on a large catchment set cannot be the sheer consequence of luck. If the piezometric measurements are well represented, both on the calibration and the validation period, this means that our mathematical representation is adequate for describing the underlying physical processes. 
https://doi.org/10.5194/hess-2021-413

Preprint. Discussion started: 16 August 2021

(c) Author(s) 2021. CC BY 4.0 License.

Code and data availability. Streamflow data are available on the Banque HYDRO website (SCHAPI, 2021), their use is limited to particular conditions. Climatic data are avaiblable upon request to Météo France for research use. Groundwater level data are available on the ADES website (BRGM, 2021); their use is conditioned to the Etalab open licence. The original version of GR6J is available in the open-source R package airGR (Coron et al., 2021).

\section{Appendix A: Detailed operation of the GR6J model}

\section{A1 Production function}

The production function is mainly composed of a production store, whose capacity $X_{1}$ is the first parameter of the model. Inputs are $P$ the daily rainfall depth and $E$ the daily potential evaporation. Rainfall is neutralised by evaporation to compute net rainfall $P_{n}$ and net evaporation $E_{n}$ :

- If $P>E$, then $P_{n}=P-E$ and $E_{n}=0$;

- Otherwise, $P_{n}=0$ and $E_{n}=E-P$.

If $P_{n}$ is positive, a part of it, $P_{s}$, feeds the production store, which has a level $S$ and a parameter $X_{1}$ :

$P_{s}=\frac{X_{1}\left(1-\left(\frac{S}{X_{1}}\right)^{2}\right) \tanh \left(\frac{P_{n}}{X_{1}}\right)}{1+\frac{S}{X_{1}} \tanh \left(\frac{P_{n}}{X_{1}}\right)} ; E_{s}=0$

Otherwise, a part $E_{s}$ of $E_{n}$ is taken from the production store:

$E_{s}=\frac{S\left(2-\frac{S}{X_{1}}\right) \tanh \left(\frac{E_{n}}{X_{1}}\right)}{1+\left(1-\frac{S}{X_{1}}\right) \tanh \left(\frac{E_{n}}{X_{1}}\right)} ; P_{s}=0$

The content of the production store is then updated by $S=S-E_{s}+P_{s}$. Part of the water content of the production store Perc percolates to the routing function:

$\operatorname{Perc}=S\left(1-\left(1+\left(\frac{4 S}{9 X_{1}}\right)^{4}\right)^{-\frac{1}{4}}\right)$

The content of the production store is updated again by $S=S-$ Perc. The quantity of water $P_{r}$ that reaches the routing part of the model is finally $P_{r}=\operatorname{Perc}+P_{n}-P_{s}$. 
https://doi.org/10.5194/hess-2021-413

Preprint. Discussion started: 16 August 2021

(c) Author(s) 2021. CC BY 4.0 License.

\section{A2 Unit hydrographs}

$P_{r}$ is divided into two components: $90 \%$ are routed through the one-sided unit hydrograph $U H_{1}$ and the remaining $10 \%$, through a two-sided unit hydrograph $U H_{2}$. The cumulated ordinates of the unit hydrographs $S H_{1}(t)$ and $S H_{2}(t)$ are determined by the basetime $X_{4}$, for $t \in \mathbb{N}$ :

$S H_{1}(t)= \begin{cases}0 & \text { if } t=0 \\ \left(\frac{t}{X_{4}}\right)^{\frac{5}{2}} & \text { if } 0<t<X_{4} \\ 1 & \text { if } t \geq X_{4}\end{cases}$

$500 S H_{2}(t)= \begin{cases}0 & \text { if } t=0 \\ \frac{1}{2}\left(\frac{t}{X_{4}}\right)^{\frac{5}{2}} & \text { if } 0<t<X_{4} \\ 1-\frac{1}{2}\left(2-\frac{t}{X_{4}}\right)^{\frac{5}{2}} & \text { if } X_{4} \leq t<2 X_{4} \\ 1 & \text { if } t \geq 2 X_{4}\end{cases}$

Ordinates $U H_{1}(t)$ and $U H_{2}(t)$ are then computed differentiating the cumulated ordinates:

$U H_{1}(t)=S H_{1}(t)-S H_{1}(t-1) ; U H_{2}(t)=S H_{2}(t)-S H_{2}(t-1)$

Finally, the respective outputs of the first unit hydrograph $Q_{9}$ and the second one $Q_{1}$ are computed through a convolution of $P_{r}$ :

$505 Q_{9}(t)=0.9 \sum_{k=1}^{\left\lfloor X_{4}\right\rfloor+1} U H_{1}(k) P_{r}(t-k+1)$

$Q_{1}(t)=0.1 \sum_{k=1}^{\left\lfloor 2 X_{4}\right\rfloor+1} U H_{2}(k) P_{r}(t-k+1)$

\section{A3 Routing stores}

This part of the model structure is composed of two branches, that of the stores - fed by $Q_{9}$ from the first unit hydrograph and the direct branch - fed by $Q_{1}$ from the second unit hydrograph. In the stores' branch, $Q_{9}$ is partitioned between the two stores, with $60 \%$ for the routing store and $40 \%$ for the exponential store. A potential exchange Exch is computed from the water content of the routing stores Rout, its capacity $X_{3}$ and the exchange parameters $X_{2}$ and $X_{5}$ : 
Exch $=X_{2}\left(\frac{\text { Rout }}{X_{3}}-X_{5}\right)$

This flux can be negative, zero or positive. Since the routing store cannot have a water content Rout under zero, the actual exchange flux from the routing store $A E x c h_{1}$ is limited by the content of the latter, which gives the following equation:

$515 A E^{2 x c h} h_{1}= \begin{cases}\text { Exch } & \text { if Rout }+0.6 Q_{9}+\text { Exch } \geq 0 \\ - \text { Rout }-0.6 Q_{9} & \text { otherwise }\end{cases}$

The routing reservoir is then filled with:

Rout $=$ Rout $+Q_{9}+$ AExch $_{1}$

And the output $Q_{R}$ of the routing reservoir is computed as:

$Q_{R}=\operatorname{Rout}\left(1-\left(1+\left(\frac{\text { Rout }}{X_{3}}\right)^{4}\right)^{-\frac{1}{4}}\right)$

The water content of the reservoir is finally updated as Rout $=$ Rout $-Q_{R}$.

As for the exponential store, it is a bottomless reservoir whose water content Exp can be negative. Therefore, no case disjunction is necessary and the store can be filled with:

$E x p=E x p+0.4 Q_{9}+E x c h$

Its output is computed, using its capacity $X_{6}$, as:

$Q_{R \operatorname{Rexp}}=X_{6} \log \left(1+\exp \left(\frac{E x p}{X_{6}}\right)\right)$

The exponential store can now be updated using $\operatorname{Exp}=\operatorname{Exp}-Q_{R \exp }$.

The second branch, fed by $Q_{1}$, is also subject to exchange $A E x c h_{2}$ with a case disjunction:

$A \operatorname{Exch}_{2}= \begin{cases}\text { Exch } & \text { if } Q_{1}+\text { Exch } \geq 0 \\ -Q_{1} & \text { otherwise }\end{cases}$

The output of the second branch $Q_{d}$ can now be computed using $Q_{d}=Q_{1}-A E x c h 2$. The simulated streamflow $Q_{\text {sim }}$ is finally computed by adding the components from the three branches:

$Q_{\text {sim }}=Q_{R}+Q_{\text {Rexp }}+Q_{d}$ 
https://doi.org/10.5194/hess-2021-413

Preprint. Discussion started: 16 August 2021

(c) Author(s) 2021. CC BY 4.0 License.

\section{Appendix B: Parameter ranges and transformations used for original and modified GR6J calibration}

Table B1. Parameter ranges and transformation functions

\begin{tabular}{llllll}
\hline Parameter & Unit & Description & Search range & Transformation function & Reciprocal transformation \\
\hline$X_{1}$ & mm & Production store capacity & $\mathbb{R}_{+}^{*}$ & $x \mapsto \log (x)$ & $x \mapsto \exp (x)$ \\
$X_{2}$ & mm/day & Inter-catchment exchange coefficient & {$[-9.99 ; 9.99]$} & Id & Id \\
$X_{3}$ & mm & Routing store capacity & $\mathbb{R}_{+}^{*}$ & $x \mapsto \log (x)$ & $x \mapsto \exp (x)$ \\
$X_{4}$ & days & Unit hydrographs time base & {$[0.5 ; 20]$} & $x \mapsto 9.99+19.98\left(\frac{x-20}{19.5}\right)$ & $x \mapsto 20+19.5\left(\frac{x-9.99}{19.98}\right)$ \\
$X_{5}$ & unitless & Inter-catchment exchange threshold & {$[-2 ; 2]$} & $x \mapsto 5.0 x$ & $x \mapsto x / 5.0$ \\
$X_{6}$ & mm & Exponential store capacity & $\mathbb{R}_{+}^{*}$ & $x \mapsto \log (x)$ & $x \mapsto \exp (x)$ \\
$X_{7}$ & unitless & Groundwater linear coefficient & ] $0 ; 4]$ & $x \mapsto 20 \sqrt{\tanh x}-10$ & $x \mapsto \operatorname{argtanh}\left(\left(\frac{x+10.0}{20.0}\right)^{2}\right)$ \\
$X_{8}$ & unitless & Groundwater linear offset & ] $0 ; 20[$ & $x \mapsto x-10$ & $x \mapsto x+10$ \\
\hline
\end{tabular}

\section{Appendix C: Table of variables}

\section{Data availability}

535 Streamflow data are available on the Banque Hydro website (SCHAPI, 2021). Groundwater level data are available on the ADES website (BRGM, 2021). The national hydrogeological reference map is available on the BD LISA website https:// bdlisa.eaufrance.fr (Brugeron et al., 2018). Climatic data are available for research purpose upon request to the French national weather service Météo France.

Author contributions. Both authors conceptualised the method. AP performed the tests on the dataset and developed the computing code. Both authors wrote the paper.

Competing interests. The authors declare that they have no conflict of interest.

Acknowledgements. This work is part of the CIPRHES project, funded by the French national research agency ANR (grant \#ANR-20CE04-0009), and a PhD funded by the French ministry of Environmental Transition (MTE). The stream network shown in maps is from the BD CARTO database (IGN, 2021). We would like to thank Delphine ALLIER (BRGM) for the help in selecting the test dataset and JeanBaptise Boissonnat (INRAE Antony) and Benoît GÉnOt (INRAE Antony, now at U.R.B.S.) for the database maintenance. We extend our warmest thanks to Charles PERRIN (INRAE Antony), Paul AstAGNEAU (INRAE Antony) and François BouRgIN (INRAE Antony) for 
https://doi.org/10.5194/hess-2021-413

Preprint. Discussion started: 16 August 2021

(c) Author(s) 2021. CC BY 4.0 License.

Table C1. Table of variables used in the document

\begin{tabular}{|c|c|c|}
\hline Variable & Unit & Description \\
\hline$\alpha$ & unitless & Composite calibration weight \\
\hline$A E x c h_{1}$ & $\mathrm{~mm} /$ day & Actual exchange of the routing store \\
\hline$A E x c h_{2}$ & $\mathrm{~mm} /$ day & Actual exchange of the direct branch \\
\hline$C(\alpha)$ & unitless & Composite calibration objective function \\
\hline$\delta_{z}$ & unitless & Piezometric anomaly \\
\hline$\delta_{z, o b s}$ & unitless & Observed piezometric anomaly \\
\hline$\delta_{z, s i m}$ & unitless & Simulated piezometric anomaly \\
\hline$E$ & $\mathrm{~mm} /$ day & Daily potential evaporation used as model input \\
\hline$E_{n}$ & $\mathrm{~mm} /$ day & Net evaporation \\
\hline$E_{s}$ & $\mathrm{~mm} /$ day & Part of evaporation withdrawn from the production store \\
\hline Exch & $\mathrm{mm} /$ day & Potential exchange flux \\
\hline Exp & $\mathrm{mm}$ & Exponential store level \\
\hline$N S E$ & unitless & Nash-Sutcliffe efficiency \\
\hline$P$ & $\mathrm{~mm} /$ day & Daily rainfall used as model input \\
\hline$P_{n}$ & $\mathrm{~mm} /$ day & Net rainfall \\
\hline$P_{r}$ & $\mathrm{~mm} /$ day & Flux reaching the routing part of the model \\
\hline$P_{s}$ & $\mathrm{~mm} /$ day & Part of rainfall filling the production store \\
\hline Perc & $\mathrm{mm} /$ day & Percolation flux \\
\hline$Q_{1}$ & $\mathrm{~mm} /$ day & Output of the two-sided unit hydrograph \\
\hline$Q_{9}$ & $\mathrm{~mm} /$ day & Output of the one-sided unit hydrograph \\
\hline$Q_{d}$ & $\mathrm{~mm} /$ day & Output of the direct branch \\
\hline$Q_{R}$ & $\mathrm{~mm} /$ day & Output of the routing store \\
\hline$Q_{\operatorname{Rexp}}$ & $\mathrm{mm} /$ day & Output of the exponential store \\
\hline$Q_{s} i m$ & $\mathrm{~mm} /$ day & Daily simulated streamflow \\
\hline Rout & $\mathrm{mm}$ & Routing store level \\
\hline$S$ & $\mathrm{~mm}$ & Production store level \\
\hline$S H_{1}(t)$ & unitless & Cumulative ordinates of the one-sided unit hydrograph \\
\hline $\mathrm{SH}_{2}(t)$ & unitless & Cumulative ordinates of the two-sided unit hydrograph \\
\hline$U H_{1}(t)$ & unitless & Ordinates of the one-sided unit hydrograph \\
\hline$U H_{2}(t)$ & unitless & Ordinates of the two-sided unit hydrograph \\
\hline$X_{1}$ & $\mathrm{~mm}$ & Production store capacity \\
\hline$X_{2}$ & $\mathrm{~mm} /$ day & Inter-catchment exchange coefficient \\
\hline$X_{3}$ & $\mathrm{~mm}$ & Routing store capacity \\
\hline$X_{4}$ & days & Unit hydrographs time base \\
\hline$X_{5}$ & unitless & Inter-catchment exchange threshold \\
\hline$X_{6}$ & $\mathrm{~mm}$ & Exponential store capacity \\
\hline$X_{7}$ & unitless & Groundwater linear coefficient \\
\hline$X_{8}$ & unitless & Groundwater linear offset \\
\hline$z$ & m NGF & Absolute groundwater level \\
\hline $\bar{z}$ & m NGF & Mean absolute groundwater level \\
\hline ZError & unitless & Error criterion on groundwater level \\
\hline$z_{o b s}$ & $\mathrm{~m}$ NGF & Absolute observed groundwater level \\
\hline$z_{\text {sim }}$ & $\mathrm{m}$ NGF & Absolute simulated groundwater level \\
\hline
\end{tabular}

their thorough proofreading which considerably improved the manuscript. Last but not least, computing codes could not have been developed without the precious expertise and availability of Olivier DELAIGUE (INRAE Antony). 
https://doi.org/10.5194/hess-2021-413

Hydrology and

Preprint. Discussion started: 16 August 2021

(c) Author(s) 2021. CC BY 4.0 License.

\section{References}

Ardia, D., Arango, J. O., and Gomez, N. G.: Jump-Diffusion Calibration using Differential Evolution, Wilmott Magazine, 55, 76-79, https: //mpra.ub.uni-muenchen.de/id/eprint/27852, 2011a.

Ardia, D., Boudt, K., Carl, P., Mullen, K. M., and Peterson, B. G.: Differential Evolution with DEoptim: An Application to Non-Convex Portfolio Optimization, The R Journal, 3, 27-34, https://journal.r-project.org/archive/2011-1/RJournal_2011-1_Ardia et al.pdf, 2011b.

Ardia, D., Mullen, K. M., Peterson, B. G., and Ulrich, J.: DEoptim: Differential Evolution in R, https://CRAN.R-project.org/package= DEoptim, version 2.2-5, 2020.

Aubert, D., Loumagne, C., and Oudin, L.: Sequential assimilation of soil moisture and streamflow data in a conceptual rainfall-runoff model, Journal of Hydrology, 280, 145-161, https://doi.org/10.1016/s0022-1694(03)00229-4, 2003a.

Aubert, D., Loumagne, C., Oudin, L., and Hégarat-Mascle, S. L.: Assimilation of soil moisture into hydrological models: the sequential method, Canadian Journal of Remote Sensing, 29, 711-717, https://doi.org/10.5589/m03-042, 2003 b.

Barthel, R.: HESS Opinions "Integration of groundwater and surface water research: an interdisciplinary problem?", Hydrology and Earth System Sciences, 18, 2615-2628, https://doi.org/10.5194/hess-18-2615-2014, 2014.

Barthel, R. and Banzhaf, S.: Groundwater and Surface Water Interaction at the Regional-scale - A Review with Focus on Regional Integrated Models, Water Resources Management, 30, 1-32, https://doi.org/10.1007/s11269-015-1163-z, 2015.

Bartlett, M. S. and Porporato, A.: A Class of Exact Solutions of the Boussinesq Equation for Horizontal and Sloping Aquifers, Water Resources Research, 54, 767-778, https://doi.org/10.1002/2017WR022056, 2018.

Bauer, D. F.: Constructing Confidence Sets Using Rank Statistics, Journal of the American Statistical Association, 67, 687-690, https://doi.org/10.1080/01621459.1972.10481279, 1972.

Bel, F., Lacroix, A., Mollard, A., David, C., Beaudoin, N., Mary, B., Vachaud, G., Vauclin, M., and Garino, B.: Une approche interdisciplinaire, pluri-échelle, multipartenaire des pollutions diffuses de l'eau : l'expérience de La Côte Saint-André (Isère), La Houille Blanche, pp. 72-79, https://doi.org/10.1051/lhb/1999074, 1999.

Bergström, S. and Forsman, A.: Development of a conceptual deterministic rainfall-runoff model, Hydrology Research, 4, 147-170, https://doi.org/10.2166/nh.1973.0012, 1973.

Bergström, S. and Sandberg, G.: Simulation of Groundwater Response by Conceptual Models, Hydrology Research, 14, 71-84, https://doi.org/10.2166/nh.1983.0007, 1983.

575 Beven, K.: Hydrograph separation?, in: Proc.BHS Third National Hydrology Symposium, pp. 3.2-3.8, Institute of hydrology, 1991.

Beven, K.: Prophecy, reality and uncertainty in distributed hydrological modelling, Advances in Water Resources, 16, 41-51, https://doi.org/10.1016/0309-1708(93)90028-e, 1993.

Beven, K.: Rainfall-Runoff Modelling, John Wiley \& Sons, Ltd, https://doi.org/10.1002/9781119951001, 2012.

Borzì, I., Bonaccorso, B., and Fiori, A.: A Modified IHACRES Rainfall-Runoff Model for Predicting the Hydrologic Response of a River Basin Connected with a Deep Groundwater Aquifer, Water, 11, 2031, https://doi.org/10.3390/w11102031, 2019.

BRGM: ADES: portail national d'accès aux données sur les eaux souterraines, https://ades.eaufrance.fr/, 2021.

Brugeron, A., Paroissien, J., and Tillier, L.: Référentiel hydrogéologique BDLISA version 2 : Principes de construction et évolutions, Rapport final RP-67489-FR, BRGM, http://infoterre.brgm.fr/rapports/RP-67489-FR.pdf, 2018.

Brunner, P. and Simmons, C. T.: HydroGeoSphere: A Fully Integrated, Physically Based Hydrological Model, Ground Water, 50, 170-176, https://doi.org/10.1111/j.1745-6584.2011.00882.x, 2011. 
Carlier, C., Wirth, S. B., Cochand, F., Hunkeler, D., and Brunner, P.: Geology controls streamflow dynamics, Journal of Hydrology, 566, 756-769, https://doi.org/10.1016/j.jhydrol.2018.08.069, 2018.

Castany, G.: Traité pratique des eaux souterraines, Dunod, 1963.

Coron, L., Thirel, G., Delaigue, O., Perrin, C., and Andréassian, V.: The Suite of Lumped GR Hydrological Models in an R package,

Environmental Modelling and Software, 94, 166-171, https://doi.org/10.1016/j.envsoft.2017.05.002, 2017.

Coron, L., Delaigue, O., Thirel, G., Dorchies, D., Perrin, C., and Michel, C.: airGR: Suite of GR Hydrological Models for PrecipitationRunoff Modelling, https://doi.org/10.15454/EX11NA, r package version 1.6.10.4, 2021.

Creutzfeldt, B., Ferré, T., Troch, P., Merz, B., Wziontek, H., and Güntner, A.: Total water storage dynamics in response to climate variability and extremes: Inference from long-term terrestrial gravity measurement, Journal of Geophysical Research: Atmospheres, 117, https://doi.org/10.1029/2011JD016472, 2012.

Dassargues, A., Maréchal, J. C., Carabin, G., and Sels, O.: On the necessity to use three-dimensional groundwater models for describing impact of drought conditions on streamflow regimes, in: Hydrological Extremes : Understanding, Predicting, Mitigating, edited by Press, I., pp. 165-170, 1999.

de Lavenne, A., Thirel, G., Andréassian, V., Perrin, C., and Ramos, M.-H.: Spatial variability of the parameters of a semi-distributed hydrological model, Proceedings of the International Association of Hydrological Sciences, 373, 87-94, https://doi.org/10.5194/piahs-373-872016, 2016.

Delaigue, O., Génot, B., Lebecherel, L., Brigode, P., and Bourgin, P.-Y.: Base de données hydroclimatiques observées à l'échelle de la France, INRAE, UR HYCAR, https://webgr.inrae.fr/base-de-donnees, 2021.

Dembélé, M., Hrachowitz, M., Savenije, H. H. G., Mariéthoz, G., and Schaefli, B.: Improving the Predictive Skill of a Distributed Hydrological Model by Calibration on Spatial Patterns With Multiple Satellite Data Sets, Water Resources Research, 56, https://doi.org/10.1029/2019wr026085, 2020.

Demirel, Özen, Orta, Toker, Demir, Ekmekcioğlu, Tayşi, Eruçar, Sağ, Sarı, Tuncer, Hancı, Özcan, Erdem, Koşucu, Başakın, Ahmed, Anwar, Avcuoğlu, Vanlı, Stisen, and Booij: Additional Value of Using Satellite-Based Soil Moisture and Two Sources of Groundwater Data for Hydrological Model Calibration, Water, 11, 2083, https://doi.org/10.3390/w11102083, 2019.

610 Eddelbuettel, D.: RcppDE: Global Optimization by Differential Evolution in C++, https://CRAN.R-project.org/package=RcppDE, r package version $0.1 .6,2018$.

Efstratiadis, A., Nalbantis, I., Koukouvinos, A., Rozos, E., and Koutsoyiannis, D.: HYDROGEIOS: a semi-distributed GIS-based hydrological model for modified river basins, Hydrology and Earth System Sciences, 12, 989-1006, https://doi.org/10.5194/hess-12-989-2008, 2008.

615 El-Nasr, A. A., Arnold, J. G., Feyen, J., and Berlamont, J.: Modelling the hydrology of a catchment using a distributed and a semi-distributed model, Hydrological Processes, 19, 573-587, https://doi.org/10.1002/hyp.5610, 2005.

Feyen, L., Vázquez, R., Christiaens, K., Sels, O., and Feyen, J.: Application of a distributed physically-based hydrological model to a medium size catchment, Hydrology and Earth System Sciences, 4, 47-63, https://doi.org/10.5194/hess-4-47-2000, 2000.

Gupta, H. V., Kling, H., Yilmaz, K. K., and Martinez, G. F.: Decomposition of the mean squared error and NSE performance criteria: Implications for improving hydrological modelling, Journal of Hydrology, 377, 80-91, https://doi.org/10.1016/j.jhydrol.2009.08.003, 2009.

Guérin, A., Devauchelle, O., Robert, V., Kitou, T., Dessert, C., Quiquerez, A., Allemand, P., and Lajeunesse, E.: Stream-Discharge Surges Generated by Groundwater Flow, Geophysical Research Letters, 46, 7447-7455, https://doi.org/10.1029/2019GL082291, 2019. 
Habets, F., Gascoin, S., Korkmaz, S., Thiéry, D., Zribi, M., Amraoui, N., Carli, M., Ducharne, A., Leblois, E., Ledoux, E., Martin, E., Noilhan, J., Ottlé, C., and Viennot, P.: Multi-model comparison of a major flood in the groundwater-fed basin of the Somme River (France), Hydrology and Earth System Sciences, 14, 99-117, https://doi.org/10.5194/hess-14-99-2010, 2010.

Hayashi, M.: Alpine Hydrogeology: The Critical Role of Groundwater in Sourcing the Headwaters of the World, Groundwater, 58, 498-510, https://doi.org/doi.org/10.1111/gwat.12965, 2020.

Herron, N. and Croke, B.: Including the influence of groundwater exchanges in a lumped rainfall-runoff model, Mathematics and Computers in Simulation, 79, 2689-2700, https://doi.org/10.1016/j.matcom.2008.08.007, 2009.

Hughes, D. A.: Incorporating groundwater recharge and discharge functions into an existing monthly rainfall-runoff model/Incorporation de fonctions de recharge et de vidange superficielle de nappes au sein d'un modèle pluie-débit mensuel existant, Hydrological Sciences Journal, 49, https://doi.org/10.1623/hysj.49.2.297.34834, 2004.

IGN: BD CARTO, Institut national de l'information géographique et forestière, https://geoservices.ign.fr/documentation/donnees/vecteur/ bdcarto, 2021.

635 Immerzeel, W. and Droogers, P.: Calibration of a distributed hydrological model based on satellite evapotranspiration, Journal of Hydrology, 349, 411-424, https://doi.org/10.1016/j.jhydrol.2007.11.017, 2008.

Jakeman, A. J. and Hornberger, G. M.: How much complexity is warranted in a rainfall-runoff model?, Water Resources Research, 29, 2637-2649, https://doi.org/10.1029/93wr00877, 1993.

Jian, J., Ryu, D., Costelloe, J. F., and Su, C.-H.: Towards hydrological model calibration using river level measurements, Journal of Hydrology: Regional Studies, 10, 95-109, https://doi.org/10.1016/j.ejrh.2016.12.085, 2017.

Khu, S.-T., Madsen, H., and di Pierro, F.: Incorporating multiple observations for distributed hydrologic model calibration: An approach using a multi-objective evolutionary algorithm and clustering, Advances in Water Resources, 31, 1387-1398, https://doi.org/10.1016/j.advwatres.2008.07.011, 2008.

Klemeš, V.: Operational testing of hydrological simulation models, Hydrological Sciences Journal, 31, 13-24, https://doi.org/10.1080/02626668609491024, 1986.

Kling, H., Fuchs, M., and Paulin, M.: Runoff conditions in the upper Danube basin under an ensemble of climate change scenarios, Journal of Hydrology, 424-425, 264-277, https://doi.org/10.1016/j.jhydrol.2012.01.011, 2012.

Käser, D. and Hunkeler, D.: Contribution of alluvial groundwater to the outflow of mountainous catchments, Water Resources Research, 52, 680-697, https://doi.org/10.1002/2014WR016730, 2016.

650 Lalot, E., Curie, F., Wawrzyniak, V., Baratelli, F., Schomburgk, S., Flipo, N., Piegay, H., and Moatar, F.: Quantification of the contribution of the Beauce groundwater aquifer to the discharge of the Loire River using thermal infrared satellite imaging, Hydrology and Earth System Sciences, 19, 4479-4492, https://doi.org/10.5194/hess-19-4479-2015, 2015.

Le Moine, N.: Le bassin versant de surface vu par le souterrain : une voie d'amélioration des performances et du réalisme des modèles pluie-débit ?, Ph.D. thesis, Université Pierre et Marie Curie, Paris, France, cemagref Antony, 2008.

655 Le Moine, N., Andréassian, V., and Mathevet, T.: Confronting surface- and groundwater balances on the La Rochefoucauld-Touvre karstic system (Charente, France), Water Resources Research, 44, https://doi.org/10.1029/2007wr005984, 2008.

Leleu, I., Tonnelier, I., Puechberty, R., Gouin, P., Viquendi, I., Cobos, L., Foray, A., Baillon, M., and Ndima, P.-O.: La refonte du système d'information national pour la gestion et la mise à disposition des données hydrométriques, La Houille Blanche, pp. 25-32, https://doi.org/10.1051//hb/2014004, 2014. 
https://doi.org/10.5194/hess-2021-413

Hydrology and

Preprint. Discussion started: 16 August 2021

(c) Author(s) 2021. CC BY 4.0 License.

Lenhardt, F., Doucet, N., Boisson, M., and Billault, P.: The Cenomanian Sands aquifer model: an effective groundwater management tool, Tech. rep., SOGREAH, http://feflow.info/fileadmin/FEFLOW/content_tagung/TagungsCD/papers/5.pdf, 2009.

Li, S., Gitau, M., Engel, B. A., Zhang, L., Du, Y., Wallace, C., and Flanagan, D. C.: Development of a distributed hydrological model to facilitate watershed management, Hydrological Sciences Journal, 62, 1755-1771, https://doi.org/10.1080/02626667.2017.1351029, 2017.

Lo, M.-H. and Famiglietti, J. S.: Effect of water table dynamics on land surface hydrologic memory, Journal of Geophysical Research, 115, https://doi.org/10.1029/2010JD014191, 2010.

Mackay, J., Jackson, C., and Wang, L.: A lumped conceptual model to simulate groundwater level time-series, Environmental Modelling \& Software, 61, 229-245, https://doi.org/10.1016/j.envsoft.2014.06.003, 2014.

Madsen, H.: Parameter estimation in distributed hydrological catchment modelling using automatic calibration with multiple objectives, Advances in Water Resources, 26, 205-216, https://doi.org/10.1016/s0309-1708(02)00092-1, 2003.

Mann, H. B. and Whitney, D. R.: On a Test of Whether one of Two Random Variables is Stochastically Larger than the Other, The Annals of Mathematical Statistics, 18, 50-60, https://doi.org/10.1214/aoms/1177730491, 1947.

McDonnell, J. J. and Beven, K.: Debates-The future of hydrological sciences: A (common) path forward? A call to action aimed at understanding velocities, celerities and residence time distributions of the headwater hydrograph, Water Resources Research, 50, 53425350, https://doi.org/10.1002/2013WR015141, 2014.

Michel, C.: Que peut-on faire en hydrologie avec modèle conceptuel à un seul paramètre ?, La Houille Blanche, pp. 39-44, https://doi.org/10.1051/lhb/1983004, 1983.

Milzow, C., Krogh, P. E., and Bauer-Gottwein, P.: Combining satellite radar altimetry, SAR surface soil moisture and GRACE total storage changes for hydrological model calibration in a large poorly gauged catchment, Hydrology and Earth System Sciences, 15, 1729-1743, https://doi.org/10.5194/hess-15-1729-2011, 2011.

Moore, R. J.: Real-Time Flood Forecasting Systems: Perspectives and Prospects, pp. 147-189, Springer Berlin Heidelberg, Berlin, Heidelberg, https://doi.org/10.1007/978-3-642-58609-5_11, 1999.

Moore, R. J. and Bell, V. A.: Incorporation of groundwater losses and well level data in rainfall-runoff models illustrated using the PDM, Hydrology and Earth System Sciences, 6, 25-38, https://doi.org/10.5194/hess-6-25-2002, 2002.

Moreda, F., Koren, V., Zhang, Z., Reed, S., and Smith, M.: Parameterization of distributed hydrological models: learning from the experiences of lumped modeling, Journal of Hydrology, 320, 218-237, https://doi.org/10.1016/j.jhydrol.2005.07.014, 2006.

Mostafaie, A., Forootan, E., Safari, A., and Schumacher, M.: Comparing multi-objective optimization techniques to calibrate a conceptual hydrological model using in situ runoff and daily GRACE data, Computational Geosciences, 22, 789-814, https://doi.org/10.1007/s10596018-9726-8, 2018.

Mullen, K., Ardia, D., Gil, D., Windover, D., and Cline, J.: DEoptim: An R Package for Global Optimization by Differential Evolution, Journal of Statistical Software, 40, 1-26, https://doi.org/10.18637/jss.v040.i06, 2011.

Nash, J. and Sutcliffe, J.: River flow forecasting through conceptual models part I — A discussion of principles, Journal of Hydrology, 10, 282-290, https://doi.org/10.1016/0022-1694(70)90255-6, 1970.

Nicolle, P., Pushpalatha, R., Perrin, C., François, D., Thiéry, D., Mathevet, T., Lay, M. L., Besson, F., Soubeyroux, J.-M., Viel, C., Regimbeau, F., Andréassian, V., Maugis, P., Augeard, B., and Morice, E.: Benchmarking hydrological models for low-flow simulation and forecasting on French catchments, Hydrology and Earth System Sciences, 18, 2829-2857, https://doi.org/10.5194/hess-18-2829-2014, 2014. 
https://doi.org/10.5194/hess-2021-413

Hydrology and

Preprint. Discussion started: 16 August 2021

(c) Author(s) 2021. CC BY 4.0 License.

Nicolle, P., Besson, F., Delaigue, O., Etchevers, P., François, D., Lay, M. L., Perrin, C., Rousset, F., Thiéry, D., Tilmant, F., Magand, C., Leurent, T., and Jacob, É.: PREMHYCE: An operational tool for low-flow forecasting, Proceedings of the International Association of Hydrological Sciences, 383, 381-389, https://doi.org/10.5194/piahs-383-381-2020, 2020.

Oudin, L., Weisse, A., Loumagne, C., and Hégarat-Mascle, S. L.: Assimilation of soil moisture into hydrological models for flood forecasting: a variational approach, Canadian Journal of Remote Sensing, 29, 679-686, https://doi.org/10.5589/m03-038, 2003.

Oudin, L., Hervieu, F., Michel, C., Perrin, C., Andréassian, V., Anctil, F., and Loumagne, C.: Which potential evapotranspiration input for a lumped rainfall-runoff model?, Journal of Hydrology, 303, 290-306, https://doi.org/10.1016/j.jhydrol.2004.08.026, 2005.

Pelletier, A. and Andréassian, V.: Hydrograph separation: an impartial parametrisation for an imperfect method, Hydrology and Earth System Sciences, 24, 1171-1187, https://doi.org/10.5194/hess-24-1171-2020, 2020.

Perrin, C., Michel, C., and Andréassian, V.: Improvement of a parsimonious model for streamflow simulation, Journal of Hydrology, 279, 275-289, https://doi.org/10.1016/s0022-1694(03)00225-7, 2003.

Pinault, J.-L., Amraoui, N., and Golaz, C.: Groundwater-induced flooding in macropore-dominated hydrological system in the context of climate changes, Water Resources Research, 41, https://doi.org/10.1029/2004WR003169, 2005.

Poncelet, C.: Modélisation hydrologique en contexte non jaugé: développements méthodologiques et conceptualisation, Ph.D. thesis, Université Pierre et Marie Curie, Paris, 2016.

Price, K. V., Storn, R. M., and Lampinen, J. A.: Differential Evolution - A Practical Approach to Global Optimization, Natural Computing, Springer-Verlag, https://doi.org/10.1007/3-540-31306-0, iSBN 540209506, 2006.

Pushpalatha, R., Perrin, C., Le Moine, N., Mathevet, T., and Andréassian, V.: A downward structural sensitivity analysis of hydrological models to improve low-flow simulation, Journal of Hydrology, 411, 66-76, https://doi.org/10.1016/j.jhydrol.2011.09.034, 2011.

Pushpalatha, R., Perrin, C., Moine, N. L., and Andréassian, V.: A review of efficiency criteria suitable for evaluating low-flow simulations, Journal of Hydrology, 420-421, 171-182, https://doi.org/10.1016/j.jhydrol.2011.11.055, 2012.

R Core Team: R: A Language and Environment for Statistical Computing, R Foundation for Statistical Computing, Vienna, Austria, https: //www.R-project.org/, 2021.

Riboust, P., Thirel, G., Moine, N. L., and Ribstein, P.: Revisiting a Simple Degree-Day Model for Integrating Satellite Data: Implementation of Swe-Sca Hystereses, Journal of Hydrology and Hydromechanics, 67, 70-81, https://doi.org/10.2478/johh-2018-0004, 2018.

Roche, P.-A., Miquel, J., and Gaume, E.: Hydrologie quantitative, Springer Paris, https://doi.org/10.1007/978-2-8178-0106-3, 2012.

SCHAPI: Banque HYDRO, http://www.hydro.eaufrance.fr/, ministère de la Transition Écologique, 2021.

Slater, L. J., Thirel, G., Harrigan, S., Delaigue, O., Hurley, A., Khouakhi, A., Prosdocimi, I., Vitolo, C., and Smith, K.: Using R in hydrology: a review of recent developments and future directions, Hydrology and Earth System Sciences, 23, 2939-2963, https://doi.org/10.5194/hess23-2939-2019, 2019.

Soulsby, C., Tetzlaff, D., Rodgers, P., Dunn, S., and Waldron, S.: Runoff processes, stream water residence times and controlling landscape characteristics in a mesoscale catchment: An initial evaluation, Journal of Hydrology, 325, 197-221, https://doi.org/10.1016/j.jhydrol.2005.10.024, 2006.

Spearman, C.: Demonstration of Formulae for True Measurement of Correlation, The American Journal of Psychology, 18, 161, https://doi.org/10.2307/1412408, 1907.

Stadnyk, T. A. and Holmes, T. L.: On the value of isotope-enabled hydrological model calibration, Hydrological Sciences Journal, 65, 1525-1538, https://doi.org/10.1080/02626667.2020.1751847, 2020. 
Stadnyk, T. A., Delavau, C., Kouwen, N., and Edwards, T. W. D.: Towards hydrological model calibration and validation: simulation of stable water isotopes using the isoWATFLOOD model, Hydrological Processes, 27, 3791-3810, https://doi.org/10.1002/hyp.9695, 2013.

Swenson, S., Yeh, P. J.-F., Wahr, J., and Famiglietti, J.: A comparison of terrestrial water storage variations from GRACE with in situ measurements from Illinois, Geophysical Research Letters, 33, https://doi.org/10.1029/2006GL026962, 2006.

Syed, T. H., Famiglietti, J. S., Rodell, M., Chen, J., and Wilson, C. R.: Analysis of terrestrial water storage changes from GRACE and GLDAS, Water Resources Research, 44, https://doi.org/10.1029/2006WR005779, 2008.

Széles, B., Parajka, J., Hogan, P., Silasari, R., Pavlin, L., Strauss, P., and Blöschl, G.: The Added Value of Different Data Types for Calibrating and Testing a Hydrologic Model in a Small Catchment, Water Resources Research, 56, https://doi.org/10.1029/2019wr026153, 2020.

Tague, C. and Grant, G. E.: Groundwater dynamics mediate low-flow response to global warming in snow-dominated alpine regions, Water Resources Research, 45, https://doi.org/10.1029/2008WR007179, 2009.

Thirel, G., Salamon, P., Burek, P., and Kalas, M.: Assimilation of MODIS Snow Cover Area Data in a Distributed Hydrological Model Using the Particle Filter, Remote Sensing, 5, 5825-5850, https://doi.org/10.3390/rs5115825, 2013.

Thiéry, D.: Forecast of changes in piezometric levels by a lumped hydrological model, Journal of Hydrology, 97, 129-148, https://doi.org/10.1016/0022-1694(88)90070-4, 1988.

Thiéry, D.: Logiciel GARDÉNIA, version v8.2. Guide d'utilisation, BRGM, Orléans, France, https://www.brgm.fr/sites/default/files/ documents/2020-11/logiciel-gardenia-v8-2-rp-62797-fr-notice.pdf, bRGM report RP-62797-FR, 2014.

Tiel, M., Stahl, K., Freudiger, D., and Seibert, J.: Glacio-hydrological model calibration and evaluation, WIREs Water, 7, https://doi.org/10.1002/wat2.1483, 2020.

Tilmant, F., Nicolle, P., Bourgin, F., Besson, F., Delaigue, O., Etchevers, P., François, D., Lay, M. L., Perrin, C., Rousset, F., Thiéry, D., Magand, C., Leurent, T., and Jacob, É.: PREMHYCE: un outil opérationnel pour la prévision des étiages, La Houille Blanche, 106, 37-44, https://doi.org/10.1051/lhb/2020043, 2020.

Tobin, B. W. and Schwartz, B. F.: Quantifying the role of karstic groundwater in a snowmelt-dominated hydrologic system, Hydrological Processes, 34, 3439-3447, https://doi.org/10.1002/hyp.13833, 2020.

Tomasella, J., Hodnett, M. G., Cuartas, L. A., Nobre, A. D., Waterloo, M. J., and Oliveira, S. M.: The water balance of an Amazonian micro-catchment: the effect of interannual variability of rainfall on hydrological behaviour, Hydrological Processes, 22, 2133-2147, https://doi.org/10.1002/hyp.6813, 2008.

Valéry, A., Andréassian, V., and Perrin, C.: 'As simple as possible but not simpler': What is useful in a temperature-based snowaccounting routine? Part 1 - Comparison of six snow accounting routines on 380 catchments, Journal of Hydrology, 517, 1166-1175, https://doi.org/10.1016/j.jhydrol.2014.04.059, 2014a.

Valéry, A., Andréassian, V., and Perrin, C.: 'As simple as possible but not simpler': What is useful in a temperature-based snow-accounting routine? Part 2 - Sensitivity analysis of the Cemaneige snow accounting routine on 380 catchments, Journal of Hydrology, 517, 11761187, https://doi.org/10.1016/j.jhydrol.2014.04.058, 2014b.

Vidal, J.-P., Martin, E., Franchistéguy, L., Baillon, M., and Soubeyroux, J.-M.: A 50-year high-resolution atmospheric reanalysis over France with the Safran system, International Journal of Climatology, 30, 1627-1644, https://doi.org/10.1002/joc.2003, 2009.

Wilcoxon, F.: Individual Comparisons by Ranking Methods, Biometrics Bulletin, 1, 80, https://doi.org/10.2307/3001968, 1945.

Wirth, S. B., Carlier, C., Cochand, F., Hunkeler, D., and Brunner, P.: Lithological and Tectonic Control on Groundwater Contribution to Stream Discharge During Low-Flow Conditions, Water, 12, https://doi.org/10.3390/w12030821, 2020. 